\title{
Optimal Shape Design of Mail-Slot Nacelle on N3-X Hybrid Wing-Body Configuration
}

\author{
Hyoungjin $\mathrm{Kim}^{1}$ \\ Science Applications International Corporation, Cleveland, OH 44135 \\ and \\ Meng-Sing Liou ${ }^{2}$ \\ NASA Glenn Research Center, Cleveland, OH 44135
}

\begin{abstract}
System studies show that a N3-X hybrid wing-body aircraft with a turboelectric distributed propulsion system using a mail-slot inlet/nozzle nacelle can meet the environmental and performance goals for $\mathrm{N}+3$ generation transports (three generations beyond the current air transport technology level) set by NASA's Subsonic Fixed Wing Project. In this study, a Navier-Stokes flow simulation of N3-X on hybrid unstructured meshes was conducted, including the mail-slot propulsor. The geometry of the mail-slot propulsor was generated by a CAD (Computer-Aided Design)-free shape parameterization. A novel body force model generation approach was suggested for a more realistic and efficient simulation of the flow turning, pressure rise and loss effects of the fan blades and the inlet-fan interactions. Flow simulation results of the N3-X demonstrates the validity of the present approach. An optimal Shape design of the mail-slot nacelle surface was conducted to reduce strength of shock waves and flow separations on the cowl surface.
\end{abstract}

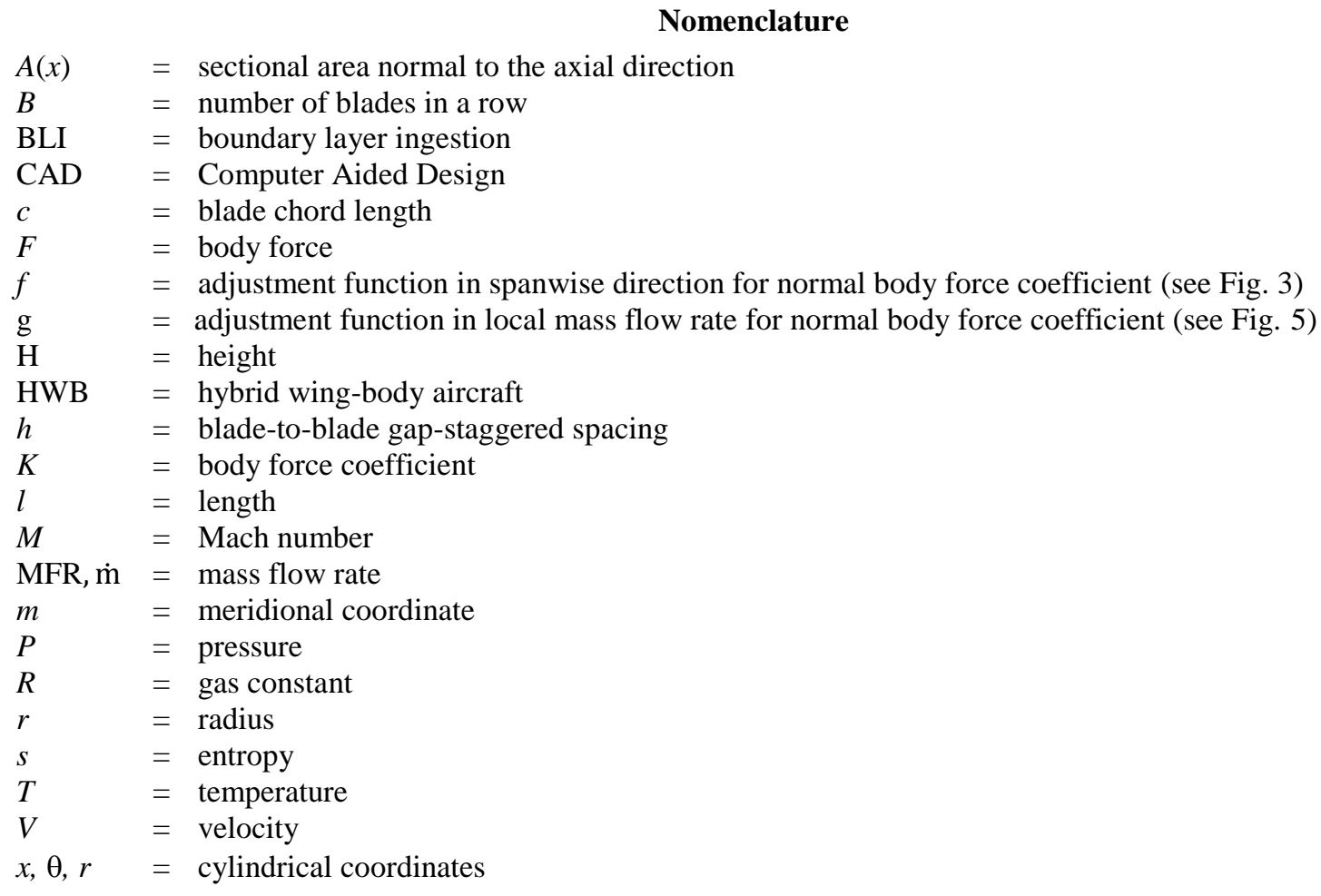

\footnotetext{
${ }^{1}$ Aerospace Engineer, Aeropropulsion Division, 3000 Aerospace Pkwy. Mail Stop VPL-2, Senior Member AIAA.

${ }^{2}$ Senior Technologist, Aeropropulsion Division, 21000 Brookpark Rd. Mail Stop 5-11, Associate Fellow AIAA
} 


$$
\begin{array}{ll}
\alpha & =\text { blade camber angle } \\
\gamma & =\text { ratio of specific heats } \\
\rho & =\text { density } \\
\sigma & =\text { solidity }
\end{array}
$$

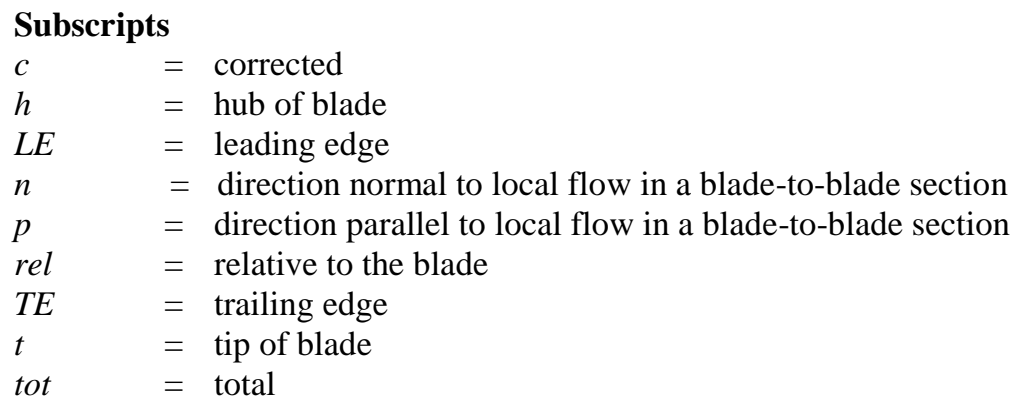

\section{Introduction}

$\mathrm{T}$ he Subsonic Fixed Wing Project of the NASA Fundamental Aeronautics Program has focused on research of the next generations of civil aircraft. For the near term $(\mathrm{N}+1)$, midterm $(\mathrm{N}+2)$, and far term $(\mathrm{N}+3)$, specific goals have been defined for reducing noise, emissions, and fuel burn from the current state-of-the-art aviation technology. ${ }^{1}$ To achieve our aggressive goals, especially for the $\mathrm{N}+2$ and $\mathrm{N}+3$ time frames, we need to explore innovative design concepts in airframes and propulsion.

The hybrid wing-body (HWB) aircraft, although not new, is an alternative design concept to the conventional tube-and-wing aircraft. ${ }^{2}$ The fuselage and wings of the HWB are integrated into a flying wing, which has better aerodynamic efficiency than tube-and-wing configurations. Also, the wide airframe body of the HWB configuration is beneficial for shielding downward-propagating noise coming from the engines that are installed above the aircraft.

In comparison to conventional pylon-mounted engines, embedded engines with boundary-layer-ingestion- (BLI) offset inlets reduce ram drag, wetted area, structural weight, and noise. ${ }^{3,4}$ Disadvantages of the embedded engines are higher flow distortion and reduced pressure recovery at the engine faces because of the BLI-offset inlet.

The $\mathrm{N} 3-\mathrm{X}$ was proposed as a candidate to meet the $\mathrm{N}+3$ goals. ${ }^{5}$ The $\mathrm{N} 3-\mathrm{X}$ is a 300 -passenger HWB aircraft employing turboelectric distributed propulsion (TeDP), which utilizes superconducting electric generators, motors, and transmission lines (see Fig. 1(a)). The TeDP system allows power generation and thrust generation to be separated and enables a small number of turboshaft engines to drive any number of propulsors, each of which is composed of an electric motor and a fan. The N3-X was designed to have two large turboshaft engines at each wing tip to feed the engines with uniform free-stream flows. In addition, BLI propulsors are distributed in the twodimensional mail-slot inlet/nozzle nacelle on the upper surface of the HWB near the trailing edge. A section view of an electric-motor-driven propulsor is depicted in Fig. 1(b). According to the system study in Ref. 5, the N3-X is expected to reduce mission fuel burn by more than 70 percent relative to a reference aircraft, a Boeing B777-200LR flying $7500 \mathrm{~nm}$ with a cruise of Mach 0.84 and a 118,100-lb payload.
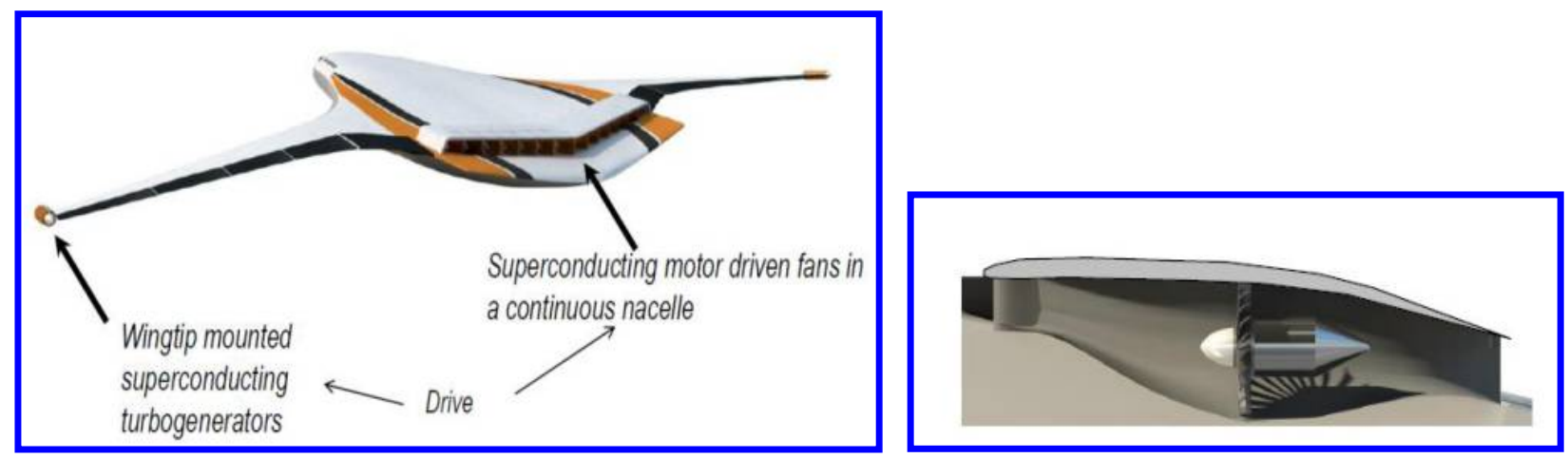

(a) Overall configuration.

(b) Section view of nacelle including fan and electric motor.

Figure 1. N3-X configuration with turboelectric distributed propulsion. ${ }^{5}$ 
The conventional uniform-back-pressure boundary condition for fan faces has been used widely to simulate flow for propulsion-airframe integration problems ${ }^{6-8}$ However, for integration problems with highly distorted onset flows at the fan faces, the assumption of uniform static pressure at the fan faces may not be valid. The low momentum at the low-recovery region at a fan face causes a larger local incidence angle for the fan rotor blade. This causes the fan to have a stronger suction effect, which, in turn, mitigates the flow distortion. Consequently, use of the uniform back-pressure boundary condition has produced conservative results for the flow distortion at fan faces, although it is still valid for the qualitative evaluation of inlet fan interaction problems when the diffuser flow separation does not reach to the fan face. ${ }^{9}$

A direct coupling ${ }^{10}$ of the inlet and full-annulus fan blades in the computational domain would give a more realistic simulation of the inlet-fan interaction, but the computational cost would be prohibitively large, especially for shape-design applications, in which more than tens of flow simulations are usually required. The body force approach $^{9,11-14}$ has been drawing attention as an alternative to simulating the coupling with full-annulus fan blades. This approach uses body force terms to model flow turning and loss due to rotor/stator blade rows. The body force terms are added as source terms in the flow equations for grid cells swept by blade rows. Body force coefficients or parameters need to be fitted to, or interpolated from, single-passage Navier-Stokes flow simulation results or experimental test data. The body force approach allows relatively accurate flow simulation of BLI inlet-fan interaction problems that consider blade force effects without actual full-annulus simulation of the rotor/stator blade rows.

In the present study, we conducted high-fidelity flow simulations of the N3-X configuration to understand the effects of the propulsion-airframe integration on the flow field and performance of the vehicle and the distributed propulsion system. A CAD-free shape parameterization was used to efficiently generate and modify the complex mail-slot nacelle geometry. An efficient body force approach was suggested to incorporate the fan blade effects of turning and flow loss. Then the nacelle cowl shape was designed to improve aerodynamic performance of the nacelle.

The remainder of this paper is organized as follows. Section II presents numerical approaches for simulating flow, including flow solvers, mesh generation method, and the body force method. Section III describes formulation of the present body force approach. Section IV presents validation results of the present body force method. Section $\mathrm{V}$ explains shape parameterization and installation approaches for the mail-slot nacelle. Section VI presents flow simulation and shape design results for the N3-X configuration. Finally, Section VII provides the summary and conclusions.

\section{A. Unstructured-Grid Flow Simulation}

\section{Methodologies for Flow Simulation}

GO-flow, ${ }^{15}$ a finite-volume unstructured-grid Navier-Stokes solver, was used for all the flow simulations in this study except turbomachinery single passage simulations. The compressible Reynolds-averaged Navier-Stokes equations were discretized by the cell-vertex finite volume method. Control volumes were nonoverlapping dual cells constructed around each node. Each edge connecting two nodes was associated with an area vector of the control surface, at which flow fluxes were computed. For second-order accuracy, a linear reconstruction of the primitive gas-dynamic variables inside the control volume was used in conjunction with a limiter. The inviscid flux was computed using approximate Riemann solvers, and Menter's two-equation Shear Stress Transport (SST) model was used to incorporate turbulence effects. ${ }^{16}$ For the time integration, the Lower-Upper Symmetric Gauss Seidel (LUSGS) implicit method was adopted. Parallel processing was accomplished by domain decomposition of the computational mesh and the Message-Passing Interface (MPI).

An unstructured computational mesh was generated with the Mixed-Element Grid Generator in 3 Dimensions (MEGG3D) code. ${ }^{17,18} \mathrm{~A}$ triangular surface mesh was generated directly on a background unstructured mesh or from stereolithography (STL) data, which can be exported from a CAD model. Then, advancing front/layer methods were used to make a hybrid volume mesh. Layers of prismatic cells were generated near viscous walls, tetrahedral cells were generated in the remaining computational domain, and pyramid cells were generated between the other cells when necessary.

\section{B. Single-passage Tubomachinery Flow Simulation}

For single-passage Navier-Stokes flow simulations of the R4 fan, the SWIFT code ${ }^{19,20}$ was used. The SWIFT code is a three-dimensional, multiblock, structured-grid Navier-Stokes analysis code for turbomachinery blade rows. 
The code solves the Navier-Stokes equations on body-fitted grids using an explicit finite-difference scheme. The AUSM+ scheme ${ }^{21}$ was used for spatial discretization of the inviscid flux. For the thin-layer approximation, viscous terms were included in the blade-to-blade and hub-to-tip directions and were neglected in the streamwise direction. For turbulence effects, Wilcox's $2006 \mathrm{k}-\omega$ model with a stress limiter was selected. The discretized equations were solved with a multistage Runge-Kutta scheme with local time stepping and residual smoothing being used to accelerate convergence.

\section{Body Force Model}

The body force model used for this study was based on the model developed by Gong, ${ }^{12}$ which makes the assumption of an infinite number of blades and axisymmetric flow in each infinitesimal blade passage. The cascade blade forces in the relative frame of reference are modeled as normal and tangential forces to the local flow, which are similar to the lift and drag forces of an airfoil.

\section{A. Normal Force Model}

In the present study, a modified formulation in Ref. 22 was used to model the normal force:

$$
F_{n}=\frac{K_{n}}{h} V_{n} V_{p}+\frac{2}{c} \sin \left(\frac{\Delta \alpha}{2}\right) V_{n}^{2}
$$

where $K_{\mathrm{n}}$ is the normal force coefficient. Equation (1) is similar to Gong's formulation except for the second term of the right-hand side. In Eq. (1), $h$ is the blade-to-blade gap-staggered spacing given by

$$
h=\frac{2 \pi r \sqrt{\sigma} \cos \alpha}{B}
$$

where $r$ is the radius, $\sigma$ is the solidity, $\alpha$ is the local blade camber angle, and $B$ is the number of blades. In Eq. (1), $V_{n}$ and $V_{p}$ are velocity components normal and parallel to the local cascade flow and are defined as follows:

$$
\begin{aligned}
& V_{n}=V_{\theta} \cos \alpha-V_{x} \sin \alpha \\
& V_{p}=V_{\mathrm{x}} \cos \alpha-V_{\theta} \sin \alpha
\end{aligned}
$$

where $V_{x}$ and $V_{\theta}$ are velocity components in the axial and circumferential directions. In the second term on the right-hand side of Eq. (1), $c$ is the chord length and $\Delta \alpha$ is the camber angle difference between the trailing edge $T E$ and leading edge $L E$ :

$$
\Delta \alpha=\alpha_{T E}-\alpha_{L E}
$$

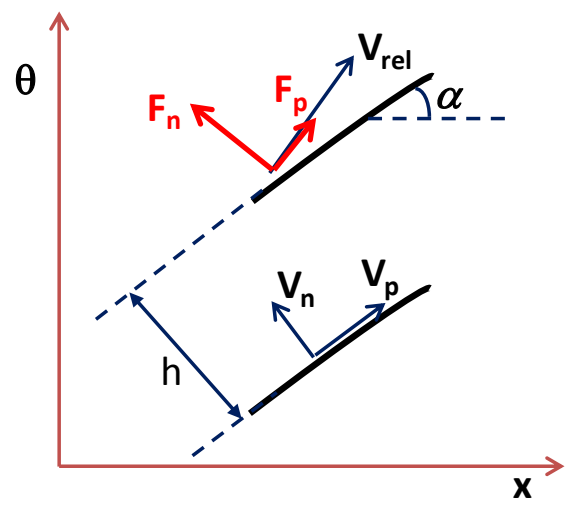

Figure 2. Illustration of body force components at blade-to-blade section 
Axial and circumferential components of the normal force are calculated by

$$
\begin{aligned}
& F_{n, x}=F_{n} \frac{V_{\theta}}{V_{r e l}} \\
& F_{n, \theta}=F_{n} \frac{V_{x}}{V_{r e l}}
\end{aligned}
$$

where $V_{\text {rel }}$ is magnitude of the blade relative velocity.

Defoe $^{23}$ suggested an empirical model for determining the normal force coefficient $K_{n}$ for a particular fan rotor:

$$
K_{n}=(4.2-3.3 \alpha)\left[4.172\left(\frac{r-r_{h}}{r_{t}-r_{h}}\right)^{2}-3.118\left(\frac{r-r_{h}}{r_{t}-r_{h}}\right)+2.145\right]
$$

where $r_{h}$ and $r_{t}$ are the hub and tip radius of the fan blade, respectively. The first expression in parentheses in Eq. (8), an empirically obtained term suggested in Ref. 12, is multiplied by the bracketed expression to adjust the magnitude of $K_{n}$ along the spanwise direction. For this study, we adopted a formulation for $K_{n}$ that is very similar to Eq. (8) but allows more flexibility:

$$
K_{n}=(4.2-3.3 \alpha) f(r)
$$

where $f(r)$ is a set of line segments connecting control points distributed along the blade span as shown in Fig. 3. The control points of $f(r)$ were adjusted to match available computational fluid dynamics (CFD) or experimental data as will be shown in Section IVA.

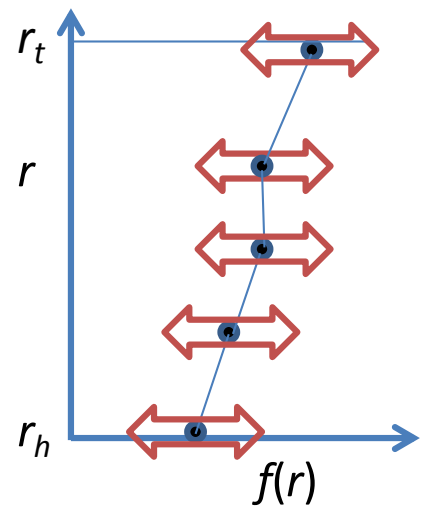

Figure 3. Definition of $f(r)$ for the body force coefficient $K_{n}$.

\section{B. Parallel Force Model}

In Gong's model, $F_{p}$, the component of the body force for the flow loss, is obtained by

$$
F_{p}=\frac{K_{p}}{h} V_{r e l}^{2}
$$

with $K_{p}=0.05$. Marble ${ }^{24}$ suggested a loss force model relating the entropy production and the parallel body force as follows:

$$
F_{p}=-T \frac{V_{m}}{V_{r e l}} \frac{\partial s}{\partial m}
$$


where $T$ is the temperature, $s$ is the entropy, and $m$ is the coordinate along the meridional streamline and $V_{m}$ is its velocity component. In this study, Marble's parallel body force model was employed instead of Gong's model because the direct relation between the parallel body force and entropy production in Eq.(11) allows an easier and physically more meaningful modeling process.

In Refs. 10 and 11, spanwise distributions of the entropy production across the blade region were used to determine the flow loss. Here, we made an assumption that the entropy production is constant along the blade span and chord for a simpler modeling procedure. Thus, we could calculate the averaged entropy change, either from test data or CFD results for the total pressure $P_{\text {tot }}$ and total temperature $T_{\text {tot }}$ ratio of a blade row, by using the canonical equation of state:

$$
\frac{\Delta s}{R}=\frac{\gamma}{\gamma-1} \ln \left(\frac{T_{t o t 2}}{T_{t o t 1}}\right)-\ln \left(\frac{P_{t o t 2}}{P_{t o t 1}}\right),
$$

where $R$ is the gas constant, $\gamma$ is the specific heat ratio, and stations 1 and 2 refer to the entrance and exit of a fan blade row, respectively. As an example, Fig. 4 shows entropy production values across a fan rotor blade row calculated by Eq. (12) with the total pressure and total temperature ratios from test data. ${ }^{25}$ In a fixed-rotor-speed line, the entropy production decreases until the minimum loss point and then increases as the MFR increases.

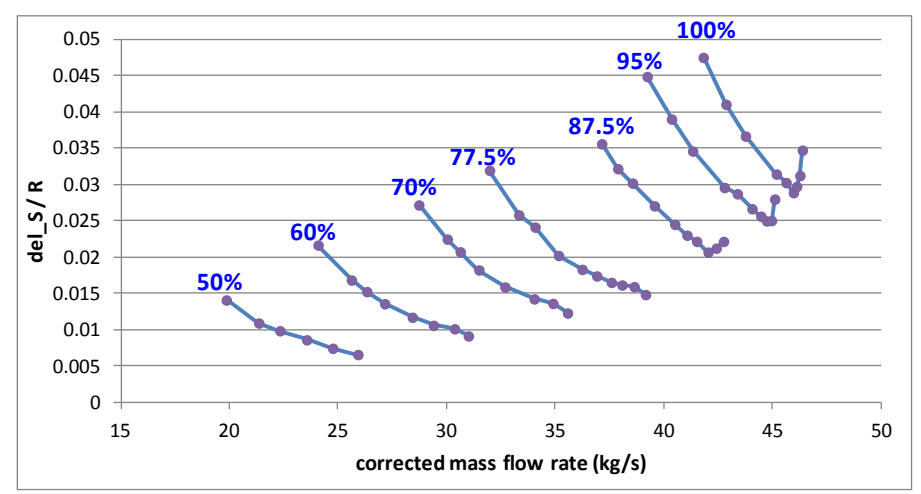

Figure 4. Mass flow rate versus entropy production of the $\mathbf{R} 4$ fan rotor blade row for different rotor speeds.

The entropy gradient in Eq. (11) is approximated by the entropy production of a blade row and the section chord length in the meridional plane at each radial location:

$$
\frac{\partial s}{\partial m} \cong \frac{\Delta s}{x_{T E}-x_{L E}}
$$

The three components of $F_{p}$ are calculated as follows:

$$
F_{p, x}=F_{p} \frac{V_{x}}{V_{r e l}}, \quad F_{p, \theta}=F_{p} \frac{V_{\theta}}{V_{r e l}}, \quad \text { and } \quad F_{p, r}=F_{p} \frac{V_{r}}{V_{r e l}}
$$

The sum of entropy production of a blade row changes as the MFR is varied at a constant rotor speed. An entropy production curve is a function of the corrected MFR. To make actual interpolations along the distributions, we need an interpolation parameter.

For structured-grid approaches having axisymmetric grid sections, each grid section is treated as an independent axisymmetric flow section, and the sectional MFR is used as the interpolation parameter for cases with a distorted inflow. ${ }^{11}$ However, validity of the parametric use of the sectional MFR for the entropy production is questionable. The use of the sectional average MFR would cause a smaller entropy production than the actual sum of local entropy production at each point of a section due to the convex nature of the entropy production distribution shown in Fig.4 especially for a distorted inflow condition. Therefore, in this study, we defined a local MFR parameter as

$$
\dot{m}_{\text {local }}=\rho V_{x} A(x)
$$


where $\rho$ and $V_{x}$ are the local density and local axial velocity, respectively, and $A(x)$ is the flow passage area normal to the axial direction. $\dot{m}_{\text {local }}$ is also corrected in the same way as the global mass flow rate.

An alternative interpolation parameter available to relate the body force model and local flow conditions is the local flow coefficient ${ }^{14}$ defined by a local axial speed divided by a local rotor speed. The present local MFR parameter allows a direct usage of entropy production curves such as shown in Fig.4, and thus a body force model can be generated in a straightforward way.

The normal body force coefficient $\mathrm{K}_{\mathrm{n}}$ is also augmented by multiplying an adjusting function $\mathrm{g}\left(\dot{m}_{\text {local }}\right)$ shown in Fig.5.

$$
K_{n}=(4.2-3.3 \alpha) f(r) g\left(\dot{m}_{\text {local }}\right)
$$

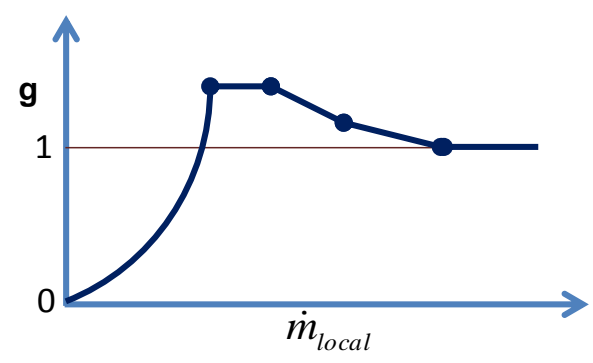

Figure 5. Illustration of an adjusting function $\mathrm{g}\left(\dot{m}_{\text {local }}\right)$ for a normal body force model.

\section{Summary of the Procedure}

A summary of the procedure for generating the body force model follows:

1) Obtain an entropy production curve for a given fan geometry and rotor speed from test data or singlepassage Navier-Stokes analyses as shown in Fig. 4.

2) Set an initial entropy production model with asymptotic lines for the target entropy production curve as shown in Fig.6. Set entropy production $\mathrm{ds}=\max (\mathrm{ds} 1, \mathrm{ds} 2)$ at each $\dot{m}_{\text {local }}$.

3) Iteratively run a three-dimensional Euler solver with the body force model and adjust slopes and intercepts of the entropy model lines to match the resulting entropy changes to the target entropy production distribution.

4) Iteratively run the Euler solver with the body force model to adjust the control parameters of function $\mathrm{g}\left(\dot{m}_{\text {local }}\right)$ in Eq. (16) to match the fan pressure ratio for the speed line. Adjust each control point of $f(r)$ separately if spanwise swirl and total pressure distributions are available and need to be matched to each other. Adjustments of fan pressure ratio parameters may require additional iterations on the entropy production model. In that case, go to Step 3).

5) If the body force model will be used in Navier-Stokes simulations, run a few Navier-Stokes simulations with the body force model to quantify the effects of the hub and shroud boundary layers on the resulting entropy production. Pull down the entropy curve functions to compensate for the redundant entropy increment in the Navier-Stokes analysis.

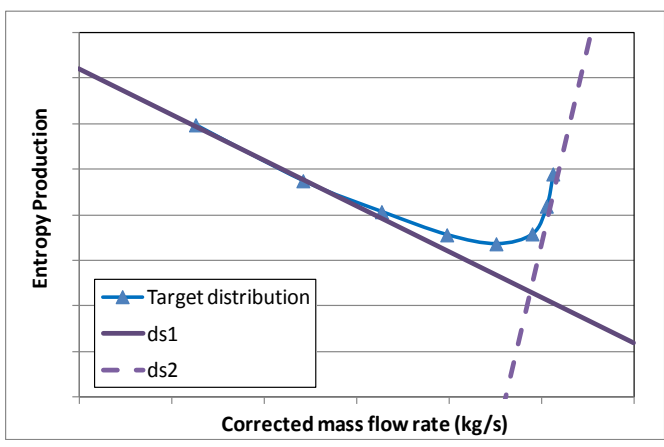

Figure 6. Illustration of initial model for entropy production variation w.r.t. local mass flow rate. 


\section{Validation of the Body Force Method}

\section{A. Uniform Inflow case}

The R4 fan stage, ${ }^{25}$ which was designed by General Electric Aircraft Engines and tested by the NASA Glenn Research Center, was selected to validate the present body force model. The R4 fan is a one-fifth scale-model representation of the bypass stage of a current-generation high-bypass turbofan engine. The fan has a 22-in. diameter and 22 wide-chord rotor blades. A Sectional side view of the R4 fan and nacelle is shown in Fig.7 (a). The stage design-point pressure ratio was 1.47 at a corrected speed of $12,657 \mathrm{rpm}$..

For single-passage Navier-Stokes flow simulations of the R4 fan, the SWIFT code ${ }^{19,20}$ was used. The SWIFT code is a three-dimensional, multiblock, structured-grid Navier-Stokes analysis code for turbomachinery blade rows and described earlier in Section II B.

An unstructured grid with tetrahedral cells was generated around the nacelle cowl, shroud, and hub of the R4 fan test geometry, and GO-flow was run in an inviscid flow simulation mode with the body-force source terms added. For the fan downstream exit boundary condition, static back pressure was imposed with the radial equilibrium condition. Figure 7(b) shows the computational mesh for the clean-inflow R4 case, and Fig. 7 shows the total pressure contours normalized by the free-stream total pressure. The total pressure increases along the streamwise direction with an almost uniform slope.

Figure 8(a) compares the fan rotor pressure ratio versus the corrected MFR at 85 percent of the design rotor speed. The test data in Ref.[25] agree very well with the results of the Swift code and the inviscid simulation with the body force model. Figure 8(b) shows that the entropy production calculated by the Euler + body force model matches the test data well. The averaged entropy production of the R4 fan rotor decreases as the MFR increases until the peak efficiency point-approximately $42 \mathrm{~kg} / \mathrm{s}$. For MFRs higher than the peak-efficiency MFR, entropy production is proportional to the MFR because the incidence angle of the blade section deviates from the minimum loss angle.

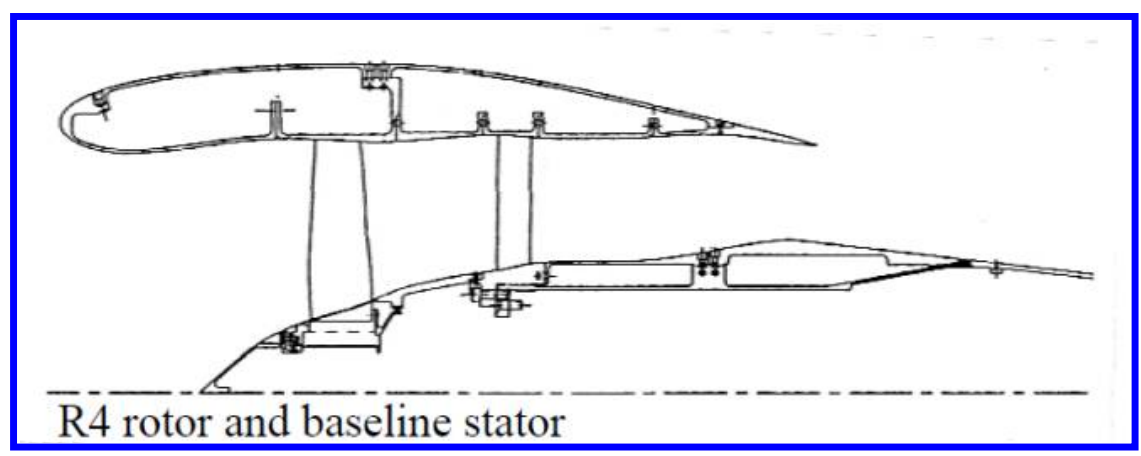

(a) Sectional geometry of the $\mathrm{R} 4$ fan and nacelle. ${ }^{25}$

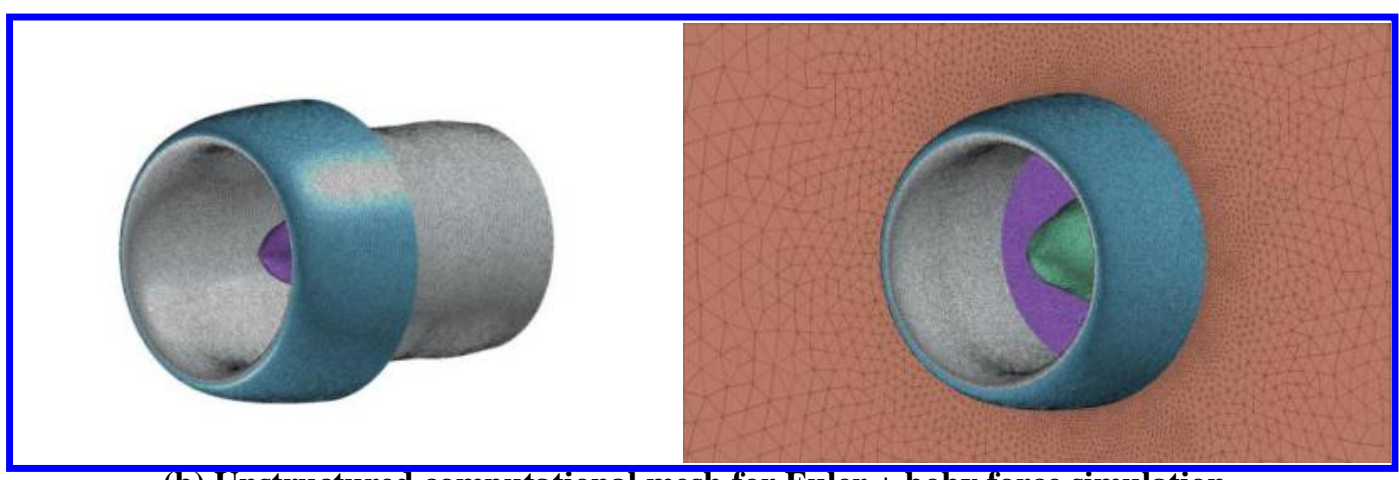

(b) Unstructured computational mesh for Euler + boby force simulation.

Figure 6. Geometry and surface mesh of the $\mathrm{R} 4$ fan and nacelle. 


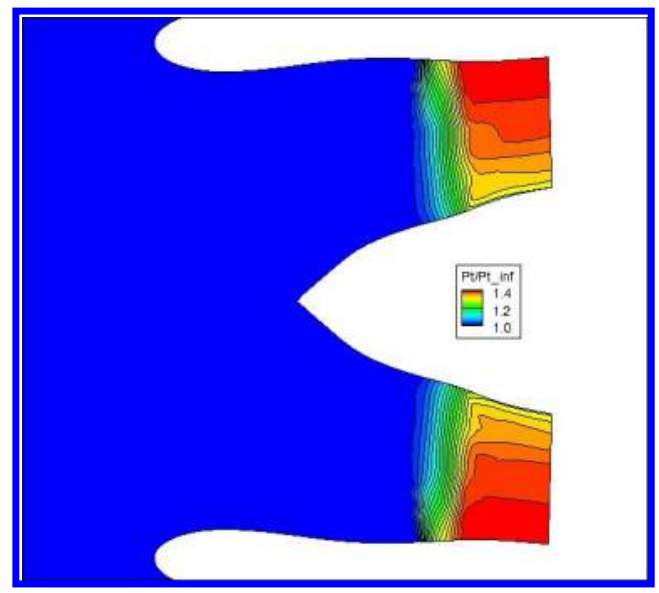

Figure 7. Euler simulation of R4 fan + nacelle with body force model: Normalized total pressure contours at a center section.

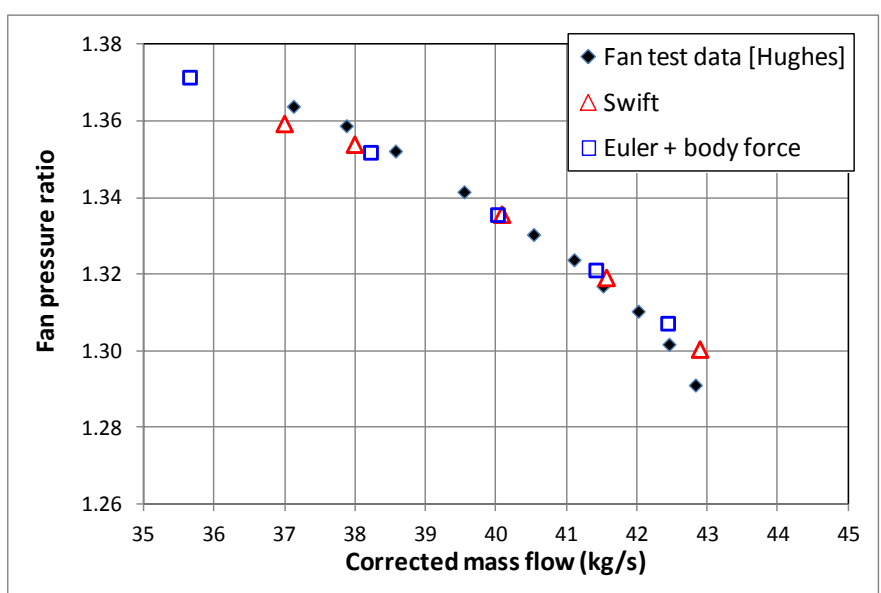

(a) Mass flow rate versus fan pressure ratio for 85-percent speed.

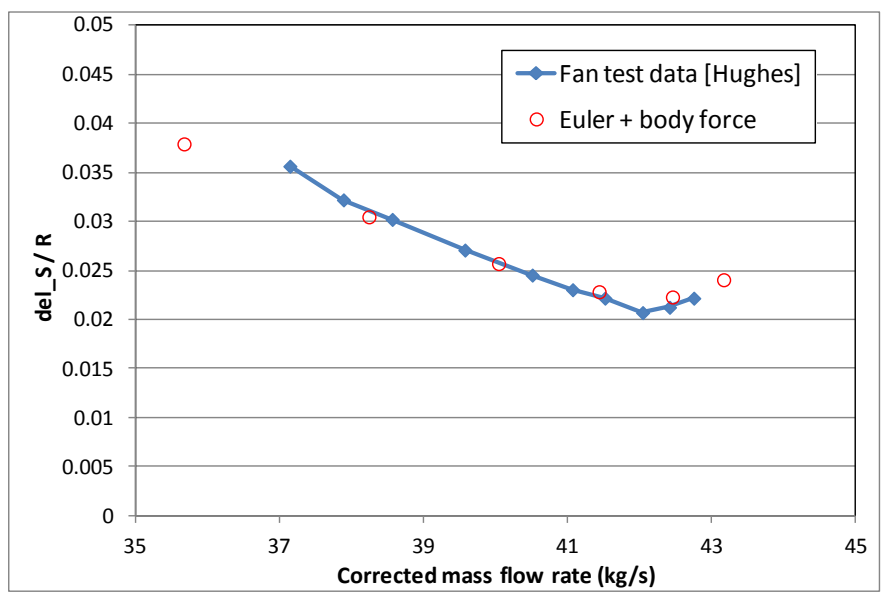

(b) Mass flow rate versus entropy production.

Figure 8. Comparison of body force model results with test data ${ }^{25}$ and the Swift code at 85-percent speed. 
In Fig. 9, spanwise distributions of flow characteristics circumferentially averaged at the rotor exit plane are compared for the Swift code and the present Euler + body force model. Actually, the control points of $f(r)$ in Section IIIA are adjusted to closely follow the trend of the swirl and the total pressure distributions for the flow conditions near the peak efficiency $\left(\dot{m}_{c}=43 \mathrm{~kg} / \mathrm{s}\right)$. Therefore, the two results are in good agreement except near the hub and shroud walls because inviscid simulations were used with the body force approach for a fast turnaround time.

As the corrected MFR decreased to $38 \mathrm{~kg} / \mathrm{s}$, as shown in Fig. 10, deviations between the Swift code and Euler+body force results became larger, but the trend was still well captured by the body force model approach. If the control points of $f(r)$ were also varied w.r.t the local mass flow rate, the body force model approach results would be improved even further. The adjustment function $\mathrm{g}\left(\dot{m}_{\text {local }}\right)$ was not applied in this case.

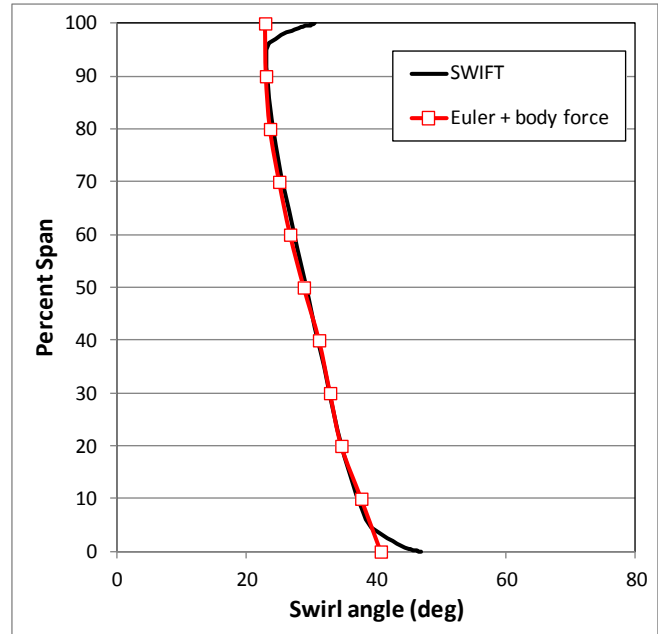

(a) Swirl-angle distribution.

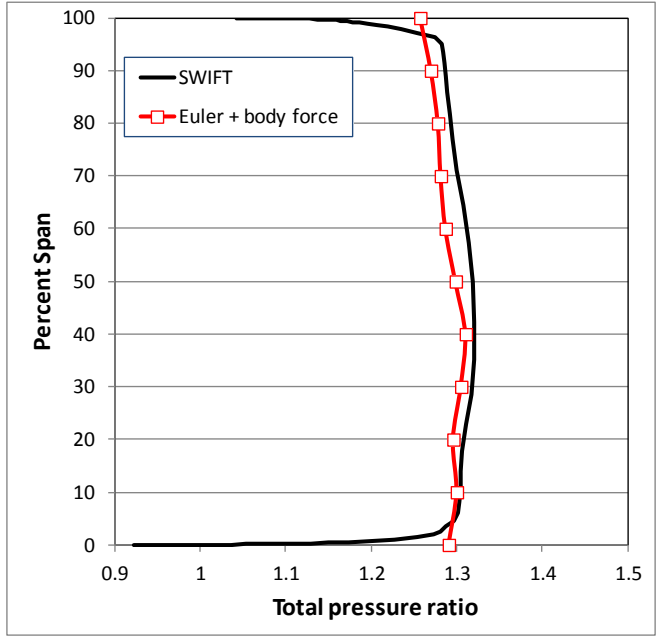

(b) Total pressure ratio distribution.

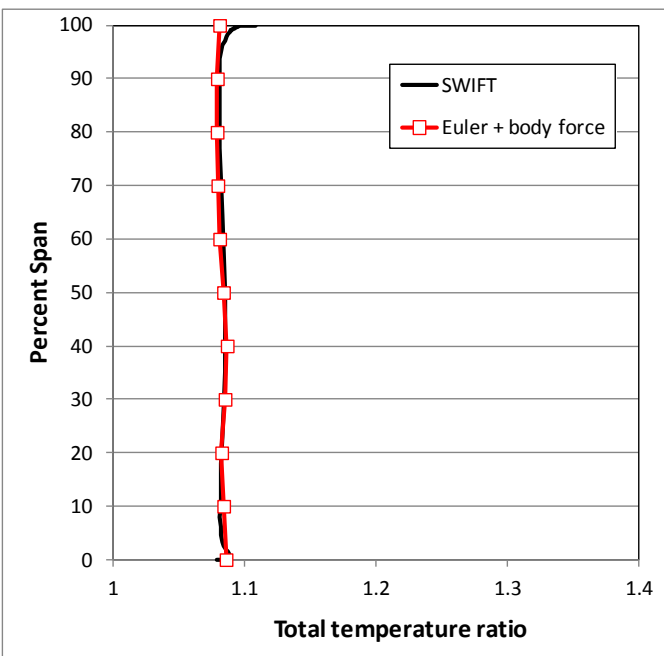

(c) Total temperature ratio distribution.

Figure 9. Comparison of rotor exit flow characteristics along the span near the choking condition $\left(\dot{m}_{c}=43\right.$

$\mathrm{kg} / \mathbf{s})$. 


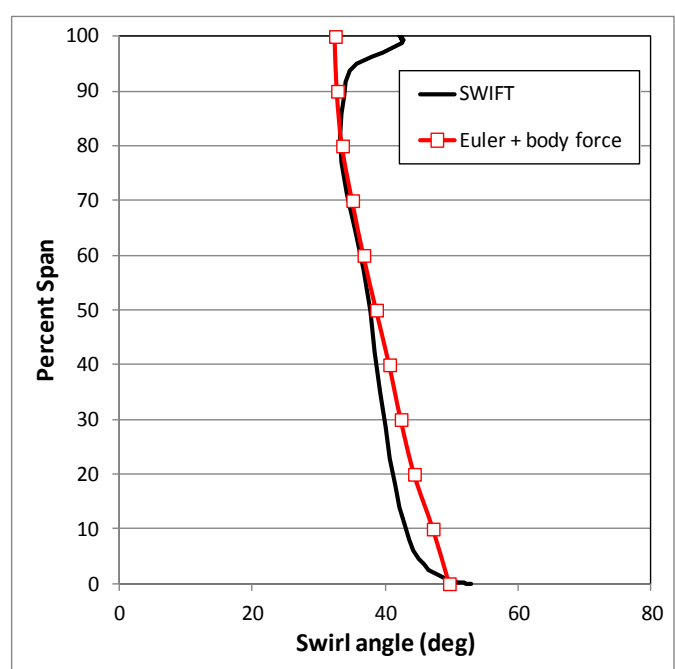

(a) Swirl angle distribution.

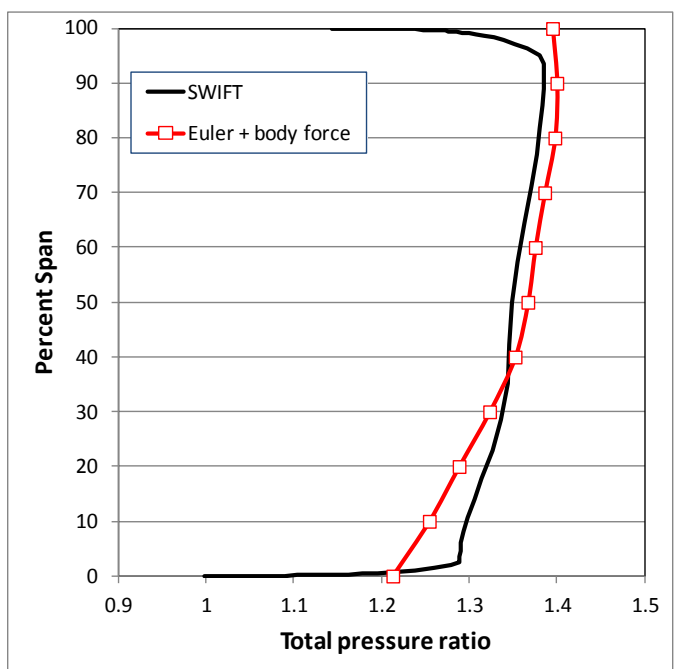

(b) Total pressure ratio distribution.

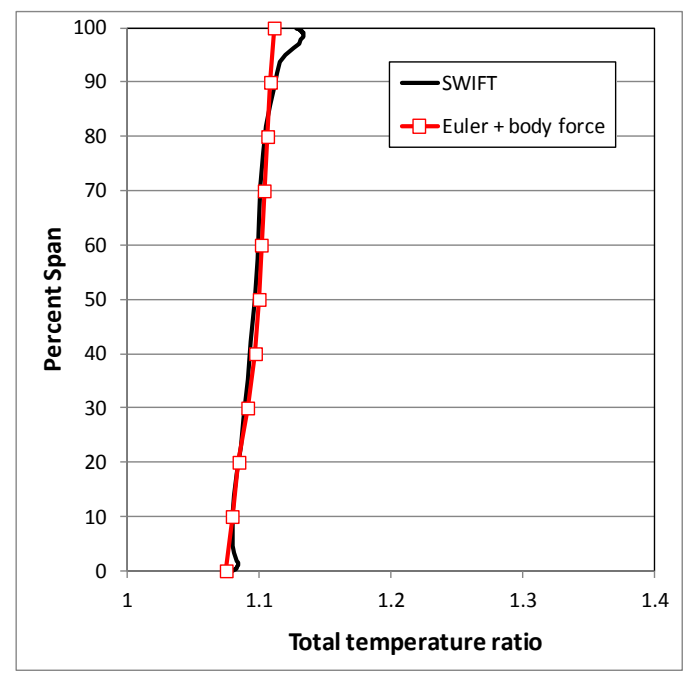

(c) Total temperature ratio distribution.

Figure 10. Comparison of rotor exit flow characteristics along the span near the surge condition $\left(\dot{m}_{c}=38 \mathrm{~kg} / \mathrm{s}\right)$.

\section{B. Non-uniform inflow case: Inlet A + R4 fan}

In Ref. [10], an unsteady unstructured grid approach was applied to simulation of a combined inlet-fan system including the whole annulus of blade rows. The mesh size was about 59.1 million. The rotor speed was $100 \%$ design speed of the R4 fan. The S-duct inlet A was scaled up and connected to the R4 fan stage as shown in Fig.11

Their results qualitatively shows that the fan performance was degraded as the distorted flow through the S-duct is fed to the fan. This case provides an excellent testbed to the validation of the body force method for distorted inflow conditions.

As a first step for the validation of the present body force method, a body force model was generated for the $100 \%$ design rotor speed of the R4 fan stage. Figure 12 shows the fan pressure ratio and entropy production variations are well matched both for fan rotor and stator stages. With the generated body force model, the inlet $\mathrm{A}+$ R4 fan stage simulations were conducted to see the validity of the model for the distorted inflows. Mesh size for the present simulation was about 30 million. Figure 13 compares the fan pressure ratio versus mass flow rate for clean and distorted inflow conditions. The present body force method shows very good agreement with the full annulus CFD results in Ref.[10]. In Fig.14, fan adiabatic efficiency was compared between the distorted inflow results by the body force approach and the clean inflow results by the test ${ }^{25}$. The distortion by the inlet A caused about $4 \%$ point reduction in the fan efficiency. 
Figure 15 compares mach contours at center plane. The results by the body force method gives qualitatively good agreements with the full annulus CFD results in Ref.[10]. Figure16 compares Mach contours at the rotor-stator interface location (the vertical blue line in Fig.11) by the full annulus CFD ${ }^{10}$ and the present body force method. The full annulus CFD captures rotor blade wakes because it performs unsteady computation. Other than that, overall trend of the distorted Mach contours are qualitatively in good agreement.

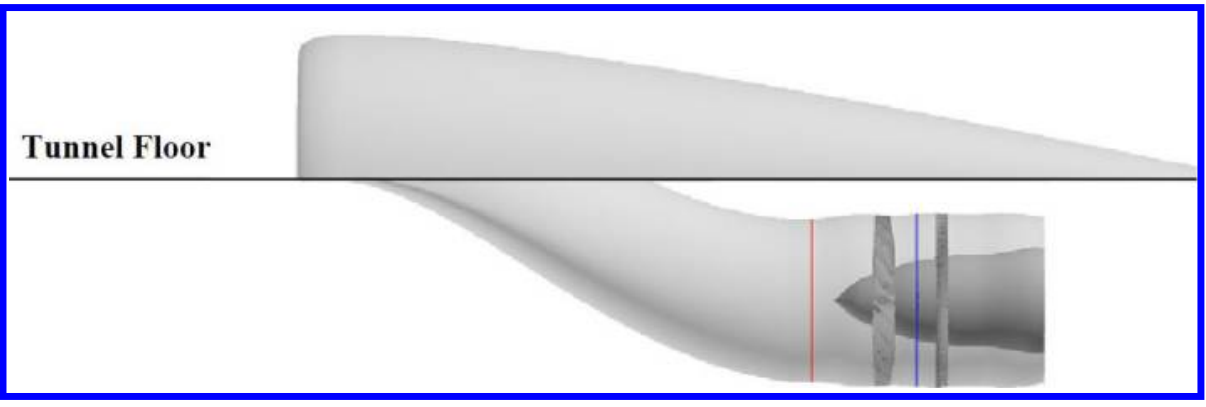

Figure 11. Side view of the combined system of the R4 fan stage and scaled inlet-A. ${ }^{10}$

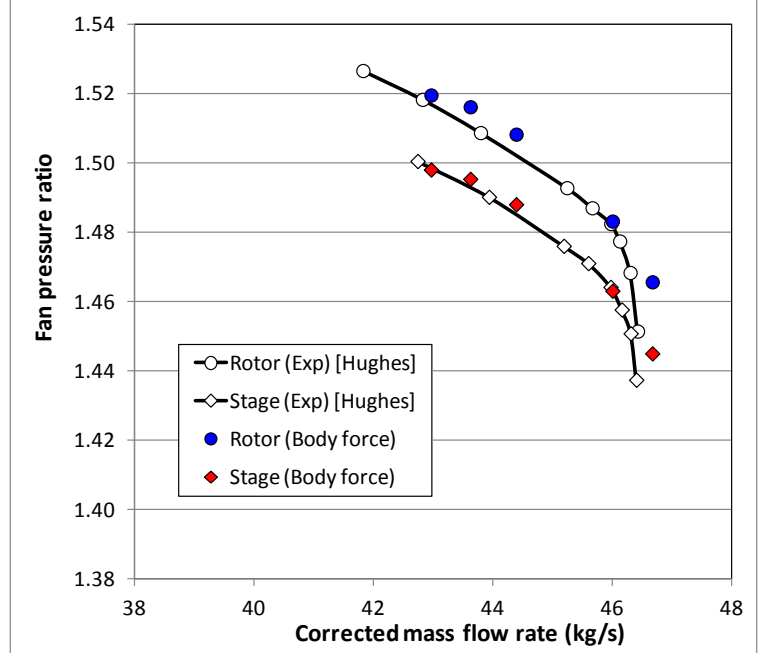

(a) Mass flow rate versus fan pressure ratio.

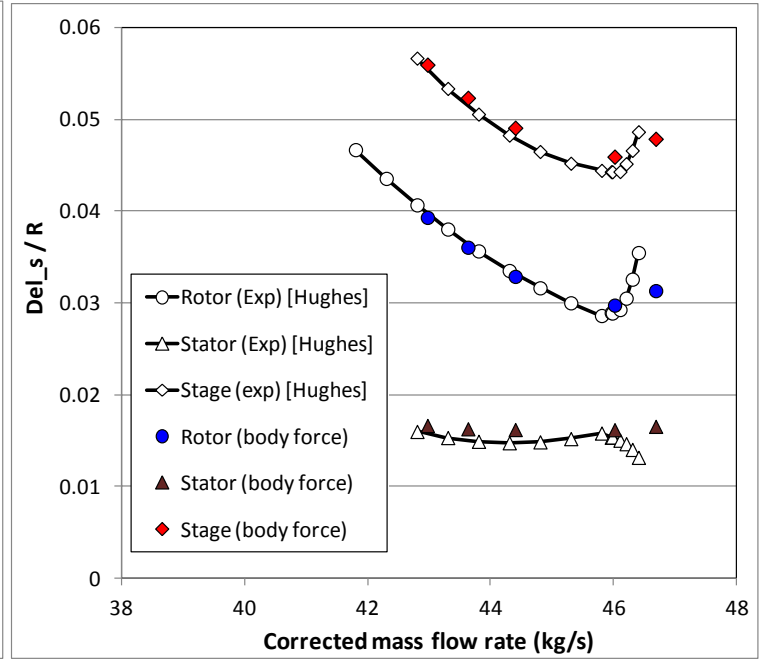

(b) Mass flow rate versus Entropy production.

Figure 12. Comparison of body force model results with test data at 100-percent speed with clean inflow . 


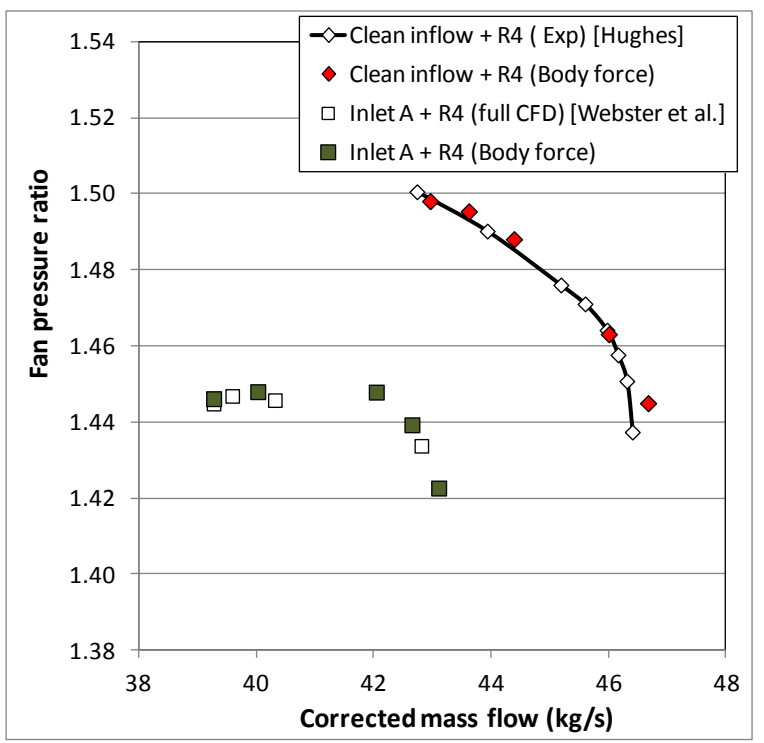

Figure 13. Comparison of body force model results with test data and full annulus CFD results at 100-percent speed for clean and distorted inflow conditions.

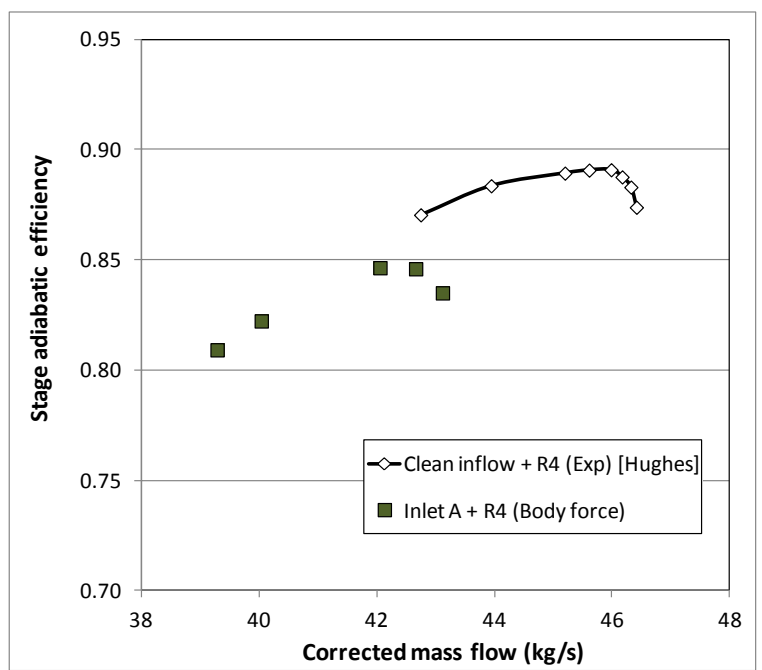

Figure 14. Comparison of stage efficiency for clean and distorted inflow conditions at 100-percent speed. 

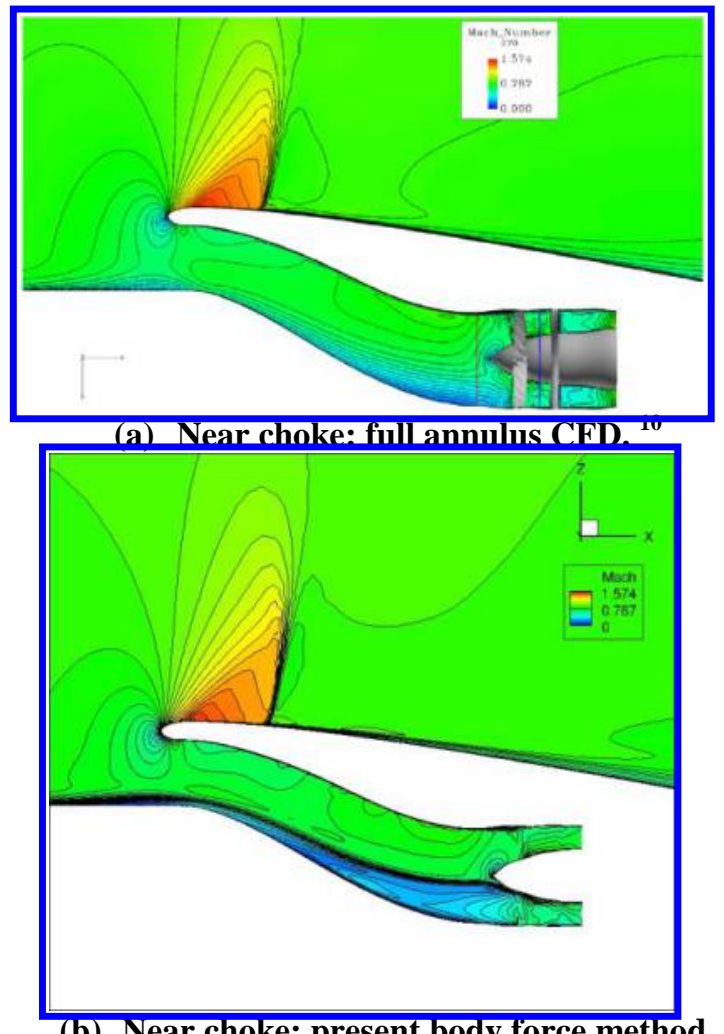

(b) Near choke: present body force method.
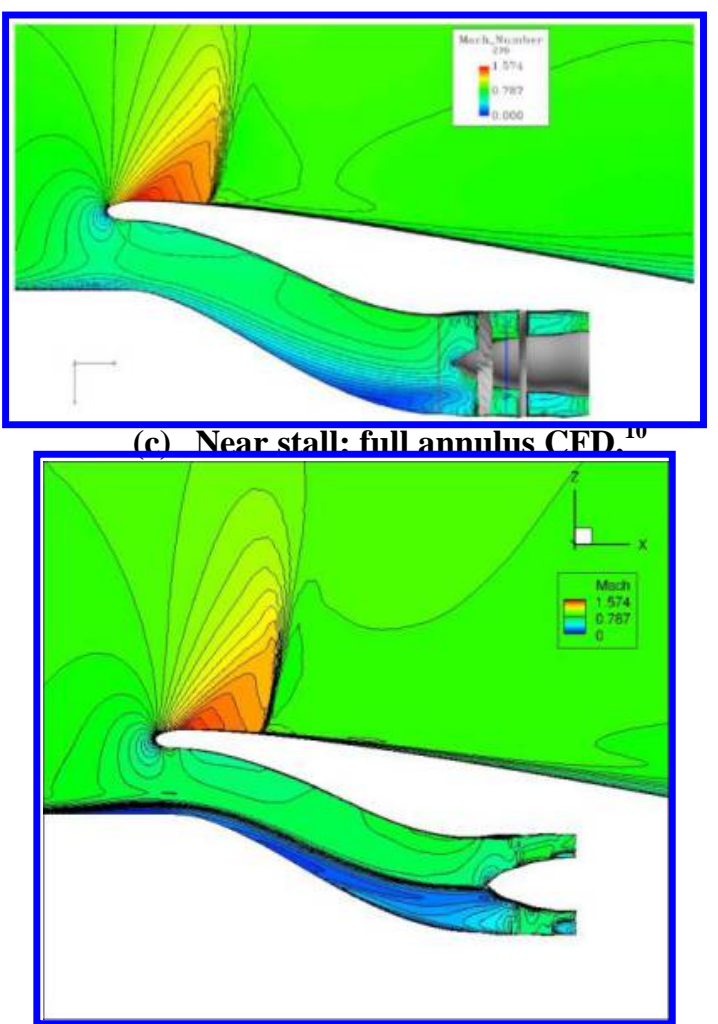

(d) Near stall: present body force method.

Figure 15. Comparison of Mach number contours by full annulus $\mathrm{CFD}^{10}$ and the present body force method at center section 


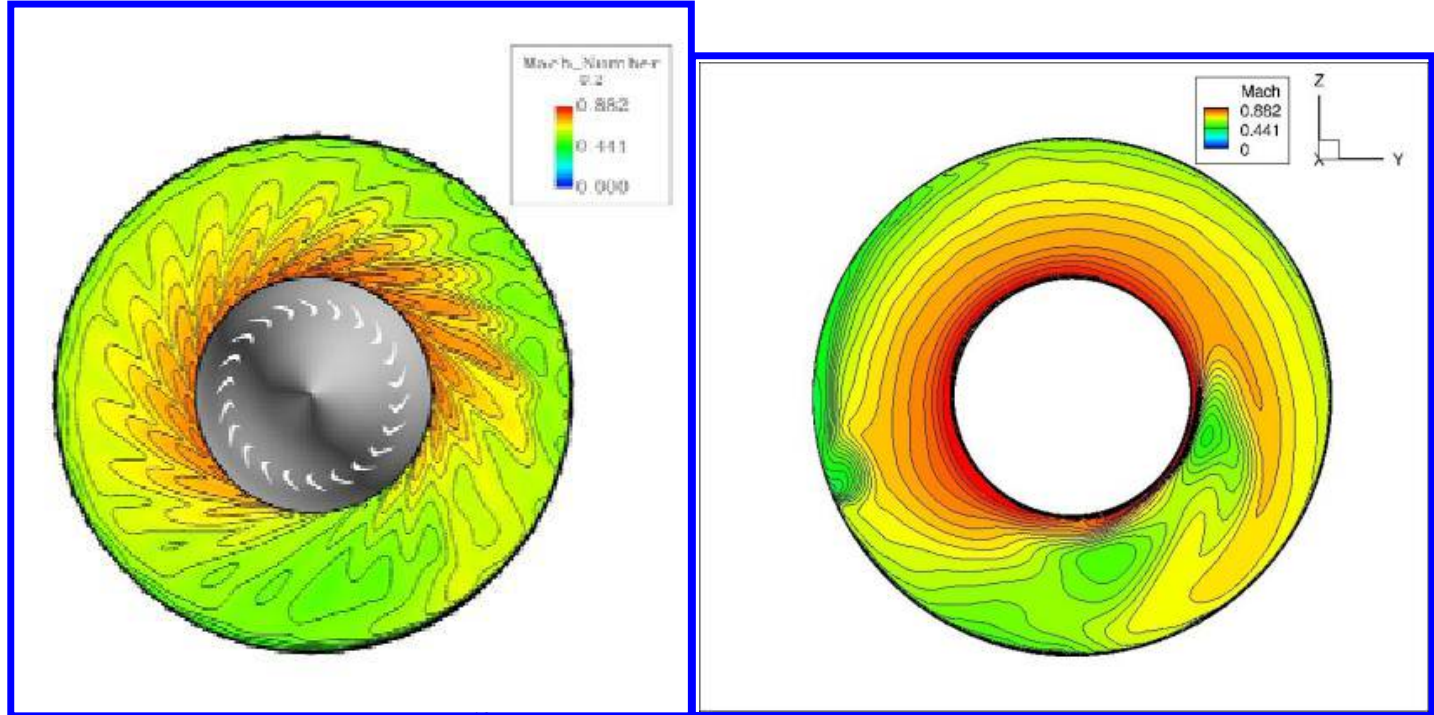

(a) Full annulus CFD. (b) Present body force method

Figure 16. Comparison of Mach number contours at rotor-stator interface position

\section{Geometry Generation of the Mail-Slot Nacelle for N3X}

A Fortran code was written that uses shape parameters to build mail-slot nacelles. The mail-slot nacelle shape can be divided into outer cowl and flow passages, each of which is composed of an S-duct inlet, a nozzle, a cylindrical duct connected to the inlet and nozzle, and a motor fairing center body. The S-duct, which is a transitional duct, has a sectional shape that transitions from a rectangle to a circle. The nozzle, which is also a transitional duct, has a sectional shape that transitions from a circle to a rectangle. In both the inlet and nozzle, the flow passages are separated by splitters.

The mail-slot propulsor is built up by 206 surface patches. Each surface patch has a structured plot3D data format. The neighboring patches are precisely joined without any gaps so that they are "water tight" and ready for unstructured surface grid generation. Figure 17 shows some parameters for the mail-slot propulsor geometry. Other parameters such as sectional areas also are defined. Any new parameters can be readily added if necessary. The computer code can be used for parametric design and optimal shape-design studies for distributed propulsion systems with a mail-slot nacelle. In the present study, the mail-slot nacelle has 16 fans and is swept forward by 25 degrees.

Once the water-tight nacelle surface patches are generated, the nacelle surface meshes are combined with an airframe surface mesh for a clean HWB configuration. After this installation, a computational unstructured surface mesh is generated on the combined configuration. The HWB airframe can be parameterized independently from the propulsor then combined with the propulsor to build the full N3-X configuration.

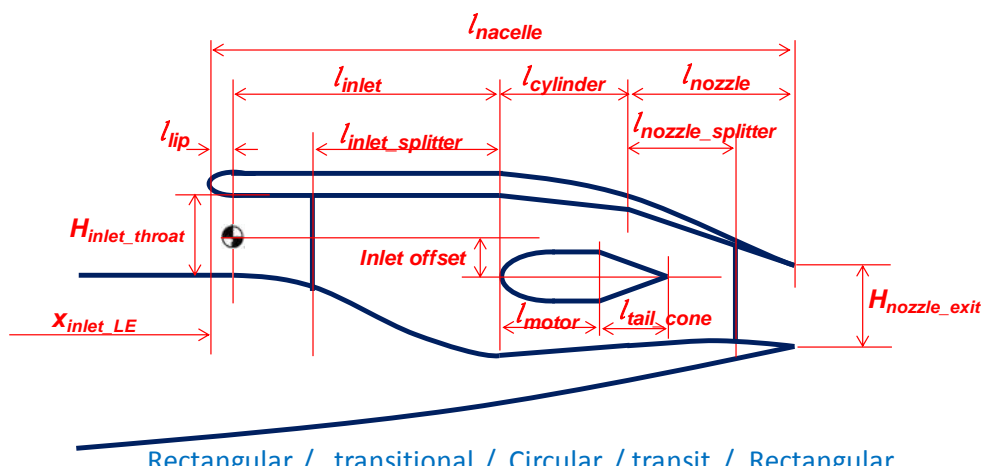

Rectangular / transitional / Circular / transit. / Rectangular

Figure 17. Side section view of schematic representation of the propulsor parameterization. 
Figure 18 shows the HWB configuration with the distributed propulsion nacelle installed on the upper surface. In the present study, the installation was made so that the leading edge of the mail-slot nacelle is located at the $85 \%$ chord position at the airframe center section. The streamwise location of the nacelle also can be modified by changing the parameter xinlet_LE in Fig. 17. The nacelle cowl follows the spanwise variation of the wing upper surface. Also, the cowl lips are twisted down in the outboard direction according to local slopes at the inlet leadingedge on the wing surface. Figure 18 (d) shows the computational mesh generated for the combined configuration. About 31 million computational mesh points are in the half model of the N3-X configuration, and the first nodes off the viscous walls are clustered to the wall so that the $y+$ values at the first nodes are less than 2 . At this point, the flow simulation could be conducted with the proper body force model for the fan blades.

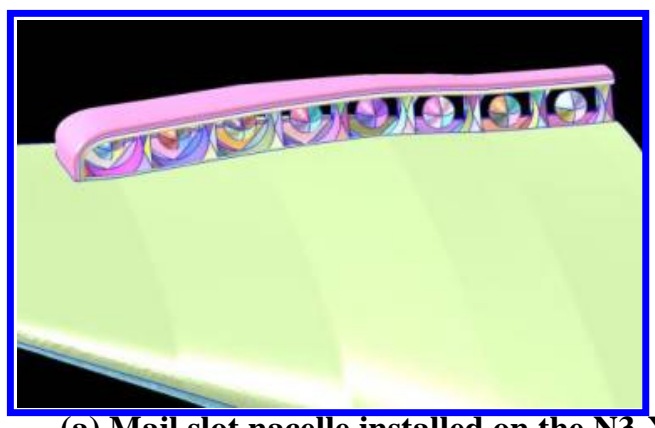

(a) Mail slot nacelle installed on the $\mathrm{N} 3-\mathrm{X}$

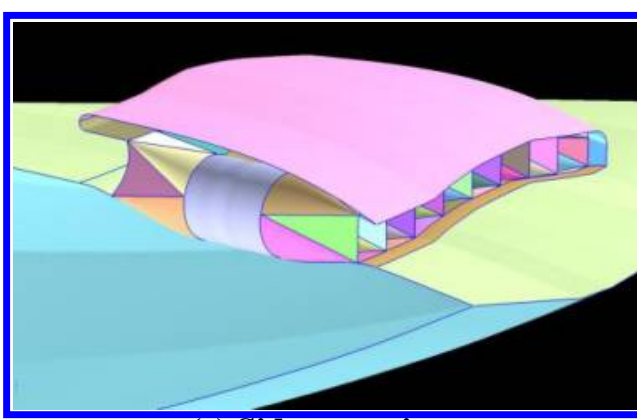

(c) Side-rear view.

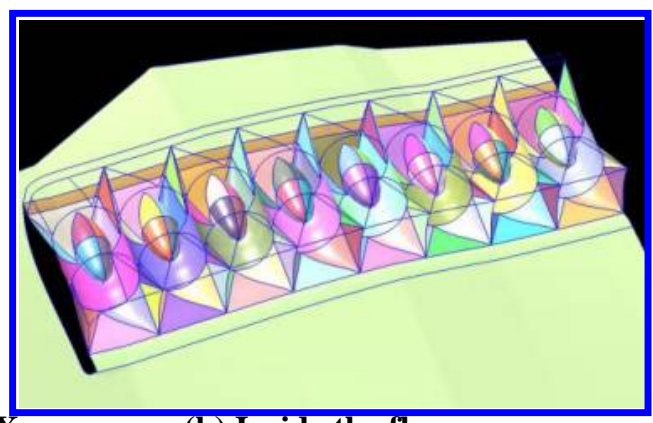

(b) Inside the flow passages.

Figure 18. N3-X configuration with installed mail-slot propulsor

\section{Flow Simulation and Shape Design Results of N3-X}

\section{A. Body Force Model Generation}

The overall size and performance specifications of the propulsor fan for N3-X were interpolated from data presented in Table 5 of Ref. 5 : fan diameter $=1.02235 \mathrm{~m}(40.25 \mathrm{in}),. \dot{m}_{c}=150.8 \mathrm{~kg} / \mathrm{s}$, pressure ratio $=1.325$, and rotor speed $=5329.575 \mathrm{rpm}_{c}$. So that a body force model could be built for an N3-X fan, the R4 fan was scaled up to have a fan diameter ratio of $40.25 / 22$ and the blade stagger angle and rotor speed were adjusted to match the specifications. The blade stagger and rotor speed were modified, and the Swift code was run to check the modifed fan's performance. Through an iterative procedure, the stagger angle was reduced by $5^{\circ}$ and the rotor speed was determined to be $5913.667 \mathrm{rpm}_{\mathrm{c}}$.

In Fig. 19, numerical results from the SWIFT code and the current Euler simulation with the body force model are well matched by the body force model. When the body force model are applied here to a viscous flow simualtion of the N3-X configuration, entropy production is increased in the viscous simulation because the hub and shroud boundary layer effects were duplicated in the Navier-Stokes simulation and the body force model. The body force model for Navier-Stokes simulations of N3-X was, therefore, corrected by reducing entropy production by 0.003 , which was obtained by comparing inviscid and viscous simulations of the R4 fan in the clean inflow conditions. The actual amount of entropy correction would vary for different flow conditions and computational meshes. 


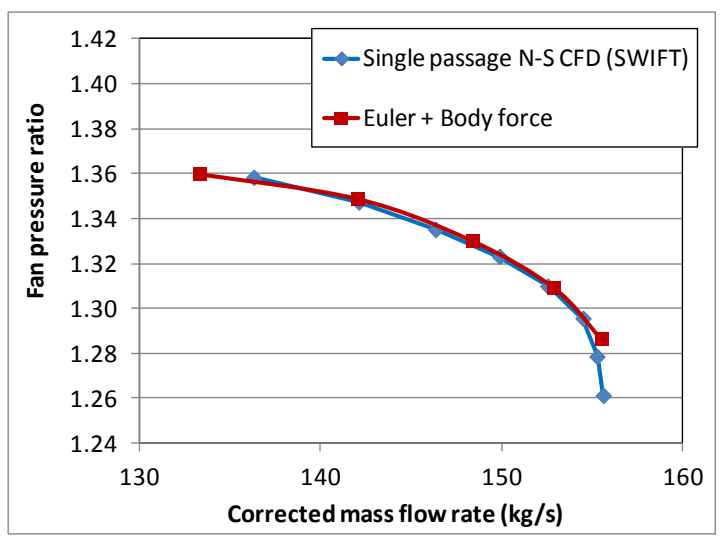

(a) Mass flow rate versus fan pressure ratio

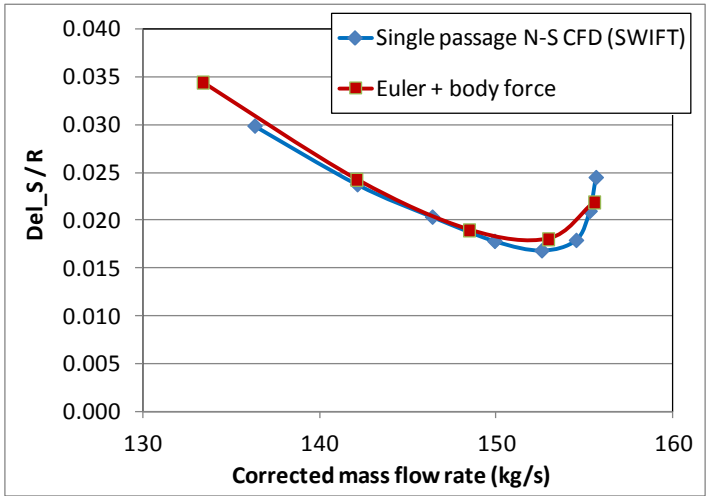

(b) Mass flow rate versus entropy production.

Figure 19. Generation of the body force model of the scaled R4 fan for installation on N3-X.

\section{B. Flow Simulation Results}

A flow simulation of the N3-X HWB configuration was conducted for a cruise flight condition: Mach 0.84 , an altitude of $35,000 \mathrm{ft}$, and an angle of attack of $2^{\circ}$.

Figure 20 shows sectional side views of total pressure contours for propulsor passages indexed by the order in the spanwise direction. The region that is swept by the fan blade and has the body force model applied can be easily recognized as the steep axial gradient of the total pressure contours around the hub forebody. It can be also noted that there is a massive leading edge separation at the nacelle inboard cowl surface and shock-induced flow separations in the mid cowl region in the spanwise direction.

The difference in the ingested boundary layer thickess can be noted from the total pressure contours. The inner passages have thicker boundary layers than the outer passages have because of the difference in distances from the airframe leading edge. Therefore, the outer passages would have higher fan face recoveries than the inner passages have. Figure 21 compares fan face pressure recoveries of the eight passages. As expected, the pressure recovery increases in overall as it goes from inboard to outboard.

Performance of the R4 fan performance was degraded in distorted inflow conditions shown in Section IV B. To check the installed performance of the present fan (staggered blade R4 fan) in the mail-slot nacells of N3-X, fan pressure ratio and adiabatic efficientcy are presented in Fig. 22. Installed fans behave independently with each other depending on the fan face distortion and corrected MFR.

\section{Shape Design Results}

To improve the aerodynamic performance of the mail-slot nacelle, the cowl surface shape was designed to minimize the aerodynamic drag using a gradient-based optimization method. Sensitivity analysis is one of the most important components to a gradient-based design optimization. The adjoint method allow efficient calculation of objective function gradients for a computational cost independent of the number of design variables. In the present study, we adopt a discrete unstructured Navier-Strokes adjoint solver ${ }^{26,27}$ developed from the flow solver described above in Section II.A. The adjoint solver uses GMRES ${ }^{28}$ for the time integration with LU-SGS as a preconditioner. Parallel processing is also made by domain decomposition of the computational mesh and Message-Passing Interface (MPI).

For geometry parameterization, CST (Class-Shape-Trasformation) method ${ }^{29}$ is employed. The CST method allows an easy specification of leading edge radius and trailing edge angles of airfoil shapes. The number of design parameters was 30: six parameters per a design section times five design sections.

The overall design procedure is as follows: First, a flow analysis is conducted for the current design configuration. Then an adjoint sensitivity analysis is performed based on the flow analysis results to determine a search direction. A step size along the search direction is selected by a line search method with the slope along the search direction. In the present study, a quadratic polynomial fitting is used for the line search. Then design variables are updated using the gradient information and step size. Design surfaces are then modified using the CST method, and volume meshes are modified accordingly using a spring analogy. This loop is repeated until the design converges, or for a limited number of iterations. As a gradient based optimizer for the unconstrained minimization problem, the conjugate gradient method $^{30}$ is used. 
Figure 23 compares Mach contours of initial and design configurations at mid region sections. By the optimal shape design, the strengths of shock waves at the mid region on the cowl surface have got remarkably reduced as shown in Fig. 23, leading to a drag reduction of 20 counts. But, there still exit flow separations in the inboard region as can be seen in Fig. 23 (a). The cowl section shapes became more thicker and convex by the design. More drastical shape change of the nacelle such as sweep angle reduction is deemed to be required to remove the large flow separation at the inboard region.

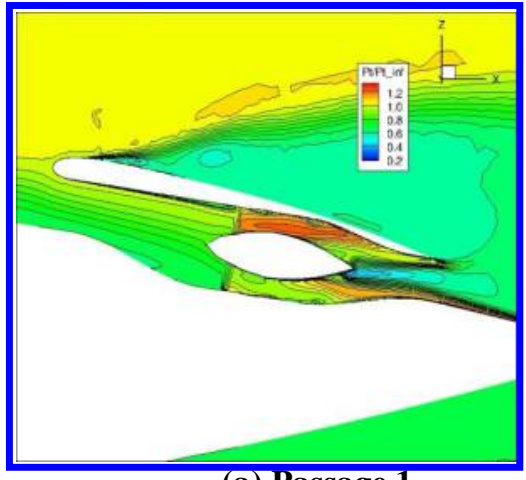

(a) Passage 1

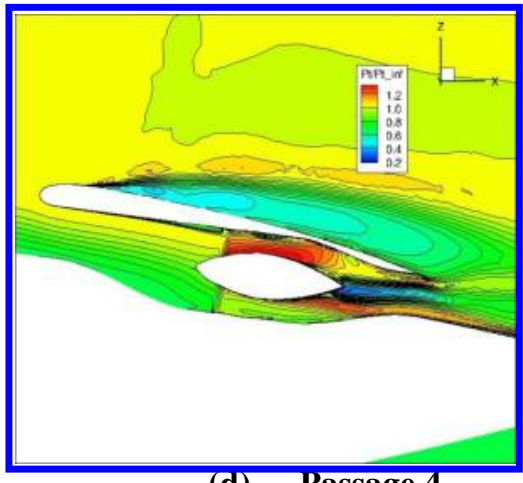

(d)

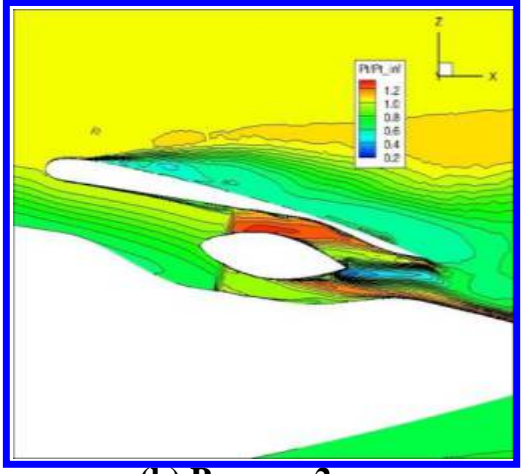

(b) Passage 2

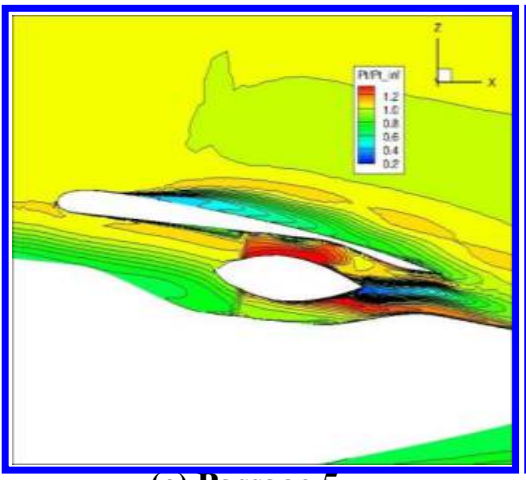

(e) Passage 5

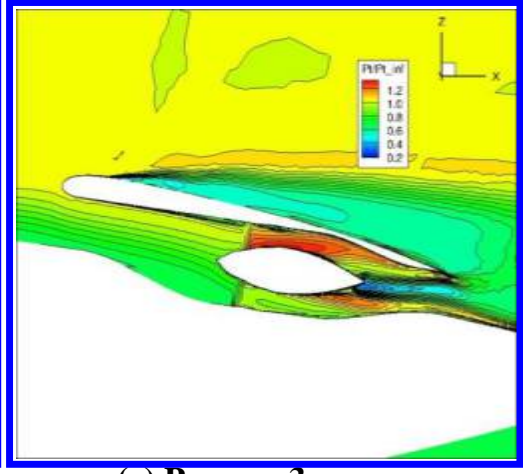

(c) Passage 3

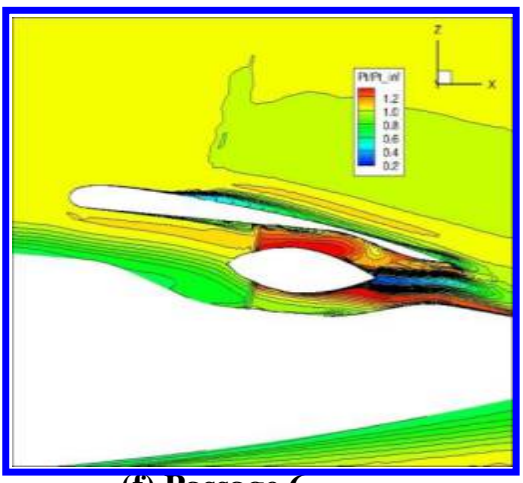

(f) Passage 6

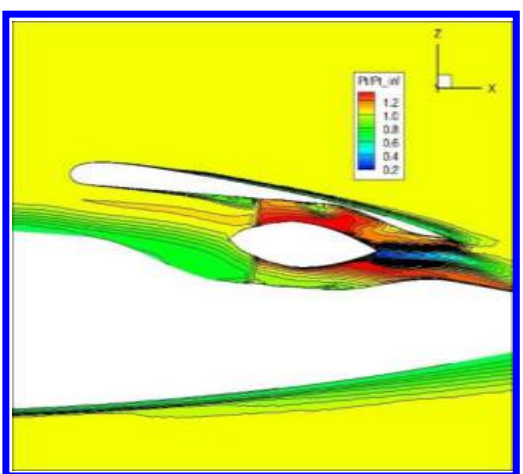

(g) Passage 7

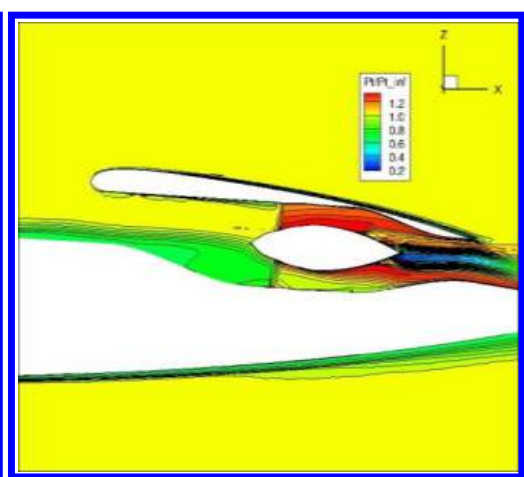

(h) Passage 8

Figure 20. Normalized total pressure contours at center section of each passage (Passage index increases from inboard to outboard). 


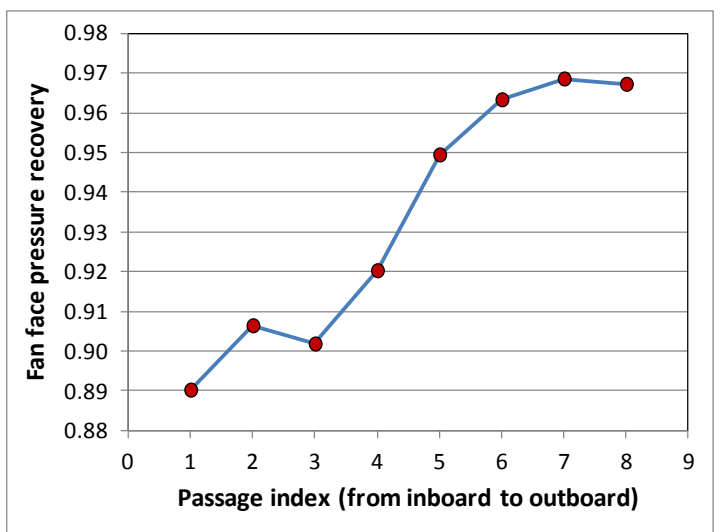

Figure 21. Comparison of fan face pressure recoveries

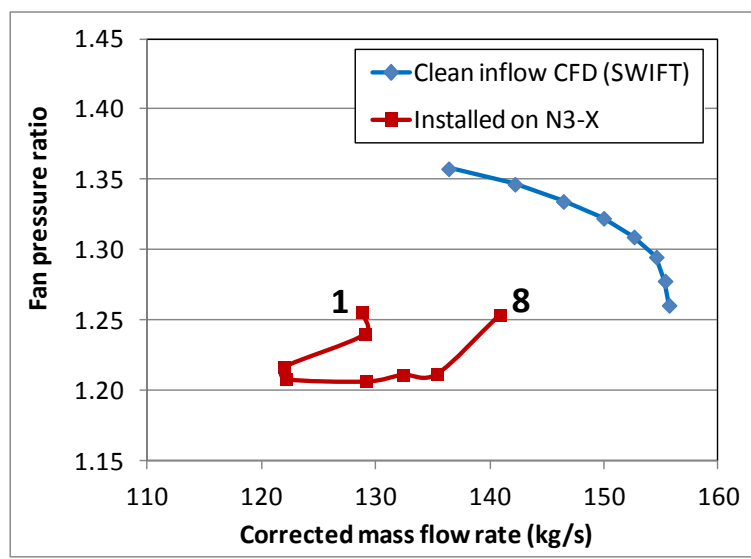

(a) Fan pressure ratio vs. MFR

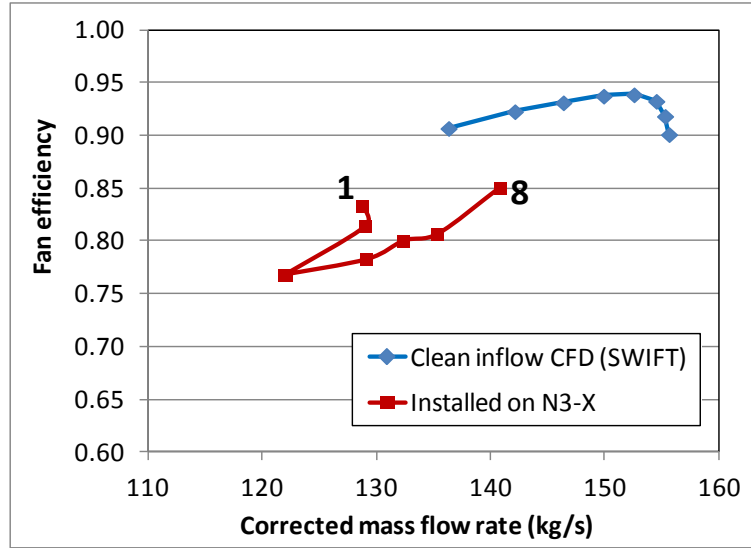

(b) Fan efficiency vs. MFR

Figure 22. Performance comparison of clean-inflow and installed fans (1: passage 1, 8: passage 8) 


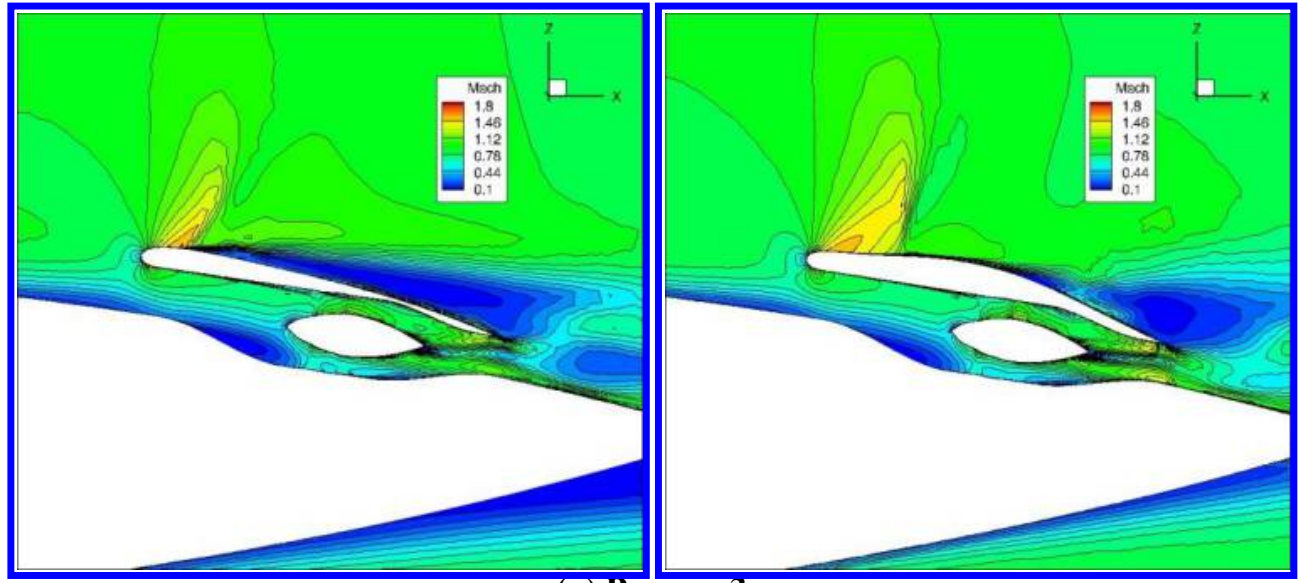

(a) Passage 3

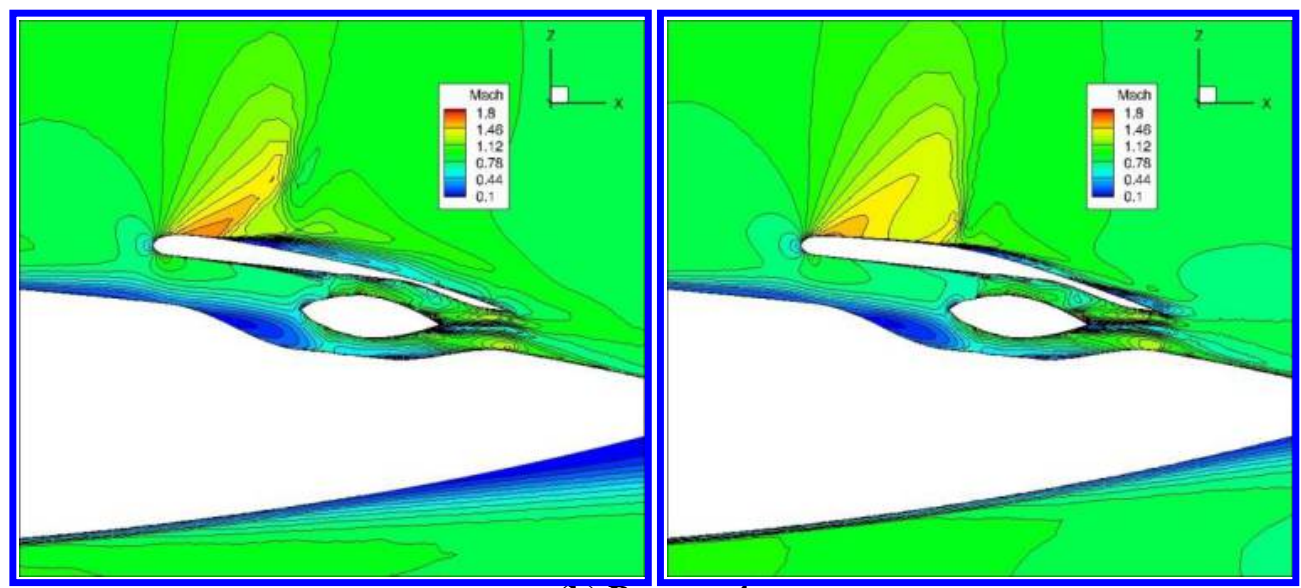

(b) Passage 4

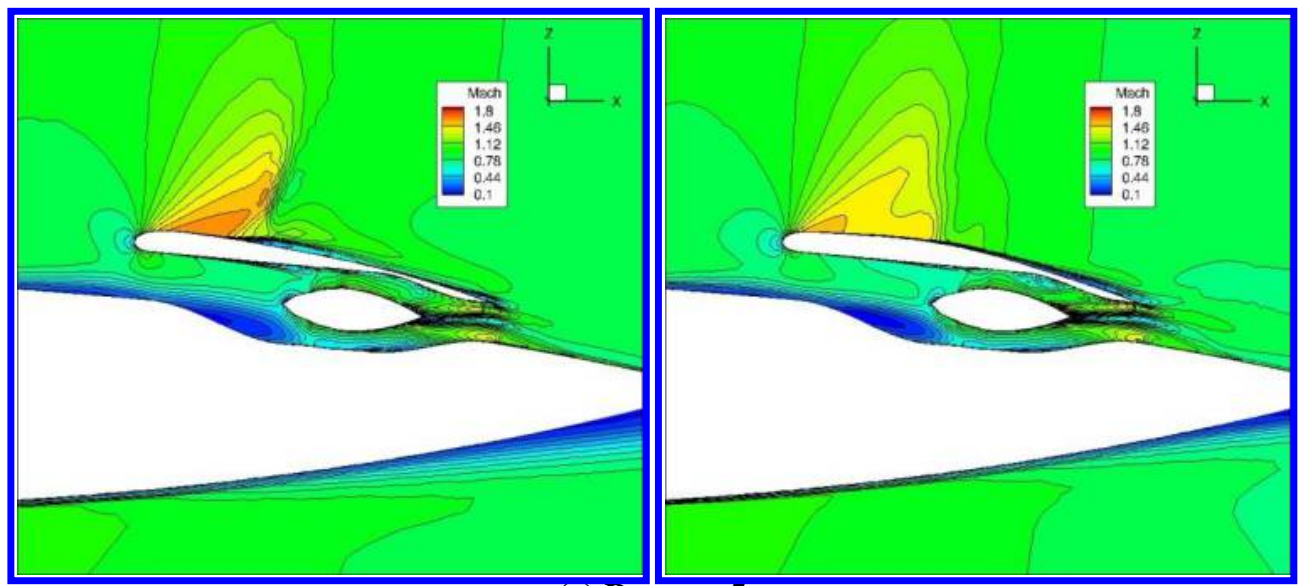

(c) Passage 5

Figure 23. Mach contours at center section of selected passages

for initial(left) and design(right) shapes

(Passage index increases from inboard to outboard). 


\section{Concluding Remarks}

High-fidelity flow simulation and optimal shape design were conducted for the N3-X hybrid wing-body configuration with the turboelectric distributed propulsion system using 16 fans in the mail-slot propulsor. The mailslot propulsor geometry was generated by an efficient CAD (computer-aided design)-free procedure. A body force model generation procedure was suggested for efficient and accurate flow simulations of inlet-fan interaction problems. Flow simulation results for the N3-X hybrid wing-body configuration with the body force model show the validity of the present approach. Also, an optimal design of the nacelle cowl shape greatly reduced the strength of show waves and flow separations on the cowl surface. Inlet shape design for improvement of the fan performance will be conducted as a future work.

\section{Acknowledgments}

The authors are grateful for the support of the NASA's Subsonic Fixed Wing Project of the Fundamental Aeronautics Program. Mr. William Haller is Technical Lead of System Analysis \& Integration Task.

\section{References}

${ }^{1}$ NASA Research and Technology Program and Project Management Requirements, NASA Procedural Requirements (NPR) 7120.9. Appendix J. Technology Readiness Levels (TRLs), Feb. 5, 2008. Available at http://nodis3.gsfc.nasa.gov/displayDir.cfm?Internal_ID=N_PR_7120_0008_\&page_name=AppendixJ

${ }^{2}$ Liebeck, R. H., "Design of the Blended Wing Body Subsonic Transport," J. Aircraft, Vol. 41, No. 1, 2004.

${ }^{3}$ Kawai, R., and Brown, D., "Acoustic Prediction Methodology and Test Validation for an Efficient Low-Noise Hybrid Wing Body Subsonic Transport," Phase I Final Report PWDM08-006A, NASA Contract Number NNL07AA54C, NASA, Oct., 2008.

${ }^{4}$ Hileman, J. I, Spakovszky, Z. S., Drela, M., Sargeant, M. A., and Jones, A., “Airframe Design for Silent FuelEfficient Aircraft,” J. Aircraft, Vol. 47, No. 3, 2010, pp. 956-969. See also AIAA Paper 2007-453, Jan., 2007.

${ }^{5}$ Felder, J., Kim, H. D., and Brown, G. V., "An Examination of the Effects of Boundary Layer Ingestion on Turboelectric Distributed Propulsion Systems," AIAA-2011-300, AIAA, 2011.

${ }^{6}$ Rodriguez, D. L., "Multidisciplinary Optimization Method for Designing Boundary Layer Ingestion Inlets," J. Aircraft, Vol. 46, No. 3, 2009, pp. 883-894.

${ }^{7}$ Kim, H., Kumano, T., Liou, M.-S., Povinelli, L. A., and Conners, T., "Numerical Propulsion Flow Simulation of Supersonic Inlet With Bypass Annular Duct," J. Propul. Power, Vol. 27, No. 1, 2011, pp. 29-39.

${ }^{8}$ O'Brien, D. M. Jr., Calvert, M. E., and Butler, S. L. "An Examination of Engine Effects on Helicopter Aeromechanics," AHS Specialist's Conference on Aeromechanics, San Francisco, CA, Jan. 23-25, 2008.

${ }^{9}$ Chima, R. V., "Rapid Calculations of Three-Dimensional Inlet/Fan Interaction," NASA Fundamental Aeronautics 2007 Annual Meeting, New Orleans, LA, Oct. 30-Nov. 1, 2007.

${ }^{10}$ Webster, R. S, Sreenivas, K., Hyams, D. G., Hilbert, B., Briley, W. R., and Whitfield, D. L. "Demonstration of Sub-system Level Simulations: A Coupled Inlet and Turbofan Stage Aerodynamic Performance of Scale-Model Turbofan Outlet Guide Vanes Designed for Low Noise," AIAA-2012-4282, 48th AIAA/ASME/SAE/ASEE Joint Propulsion Conference \& Exhibit 30 July - 01 August 2012, Atlanta, GA.

${ }^{11}$ Chima, R. V., "A Three-Dimensional Unsteady CFD Model of Compressor Stability,” GT2006-90040, ASME, 2006.

${ }^{12}$ Gong, Y., "A Computational Model for Rotating Stall Inception and Inlet Distortion in Multistage Compressors," Ph.D. Dissertation, Massachusetts Institute of Technology, Dept of Aeronautics and Astronautics, 1998.

${ }^{13}$ Hsiao, E., Naimi, M., Lewis, J. P., Dalbey, K., Gong, Y., and Tan, C., "Actuator Duct Model of Turbomachinery Components for Powered-Nacelle Navier-Stokes Calculations," J. Propul. Power, Vol. 17, No. 4, 2001, pp. 919-927.

${ }^{14}$ Walker, T. K., "The Development and Requirements of a Body Force Database from Two-Dimensional and Streamline Curvature Calculations," M.S. Thesis, Massachusetts Institute of Technology, Dept of Aeronautics and Astronautics, 2009.

${ }^{15}$ Kim, H., Kumano, T., Liou, M.-S., Povinelli, L. A., and Conners, T., "Numerical Propulsion Flow Simulation of Supersonic Inlet with Bypass Annular Duct,” J. Propul. Power, Vol. 27, No. 1, 2011, pp. 29-39.

${ }^{16}$ Menter, F. R, "Two-Equation Eddy-Viscosity Turbulence Models for Engineering Applications," AIAA J., Vol. 32, No. 8, 1994, pp. 1598-1605. 
${ }^{17}$ Ito, Y., and Nakahashi, K., "Direct Surface Triangulation Using Stereolithography Data,” AIAA J., Vol. 40, No. 3, 2002, pp. 490-496.

${ }^{18}$ Ito, Y., Shih, A. M., Soni, B. K., and Nakahashi, K., "Multiple Marching Direction Approach to Generate High Quality Hybrid Meshes,” AIAA J., Vol. 45, No. 1, 2007, pp. 162-167.

${ }^{19}$ Chima, R. V., "Calculation of Multistage Turbomachinery Using Steady Characteristic Boundary Conditions," AIAA 98-0968. Also NASA TM-1998-206613, 1998.

${ }^{20}$ Chima, R. V. and Liou, M.-S., "Comparison of the AUSM+ and H-CUSP Schemes for Turbomachinery Applications," AIAA 2003-4120. Also NASA TM-2003-2212457, 2003.

${ }^{21}$ Liou, M.-S., “A sequel to AUSM, Part II: AUSM+-up for all speeds,” J. Comput. Phys., Vol. 214, No. 1, 2006, pp. 137-170.

${ }^{22}$ WIND-US User's Guide, TURBOSPEC - MIT actuator duct (block), http://www.grc.nasa.gov/WWW/ winddocs/user/keywords/turbospec.html [last updated 21 Apr. 2010; cited 19 Dec. 2012.]

${ }^{23}$ Defoe, J., "Inlet Swirl Distortion Effects on the Generation and Propagation of Fan Rotor Shock Noise," Ph.D. Dissertation, Massachusetts Institute of Technology, Dept. of Aeronautics and Astronautics, 2011.

${ }^{24}$ Marble, F. E., "Three-Dimensional Flow in Turbomachines," in High Speed Aerodynamics and Jet Propulsion, Vol X, Aerodynamics of Turbines and Compressors, Hawthorne, W. R. ed. Princeton University Press, Princeton, NJ., 1964, pp.83-165.

${ }^{25}$ Hughes, C. E., “Aerodynamic Performance of Scale-Model Turbofan Outlet Guide Vanes Designed for Low Noise," AIAA-2002-0374, AIAA, 2002. Also NASA/TM-2001-211352, 2011.

${ }^{26}$ Kim, H., Sasaki, D., Obayashi, S., and Nakahashi, K., "Aerodynamic Optimization of Supersonic Transport Wing Using Unstructured Adjoint Method," AIAA J. Vol. 39, No. 6, pp. 1011-1020, June 2001.

${ }^{27}$ Kim, H. and Nakahashi, K., "Unstructured Adjoint Method for Navier-Stokes Equations," JSME International J. Series B, Vol. 48, No.2, pp. 202-207, May 2005.

${ }^{28}$ Y. Saad and M.H. Schultz, "GMRES: A generalized minimal residual algorithm for solving nonsymmetric linear systems", SIAM J. Sci. Stat. Comput., 7:856-869, 1986.

${ }^{29}$ Kulfan, B. M., "Universal Parameteric Geometry Representation Method," J. Aircraft Vol. 45, No.1, Jan.-Feb. 2008, pp.142-158.

${ }^{30}$ Vanderplaats, G. N., Numerical Optimization Techniques for Engineering Design: With Applications, pp. 8889, McGraw Hill, N.Y., 1984. 